\title{
Numerical Investigation of Particulate Matter Processes in Gasoline Direct Injection Engines through Integrated Computational Fluid Dynamics-Chemical Kinetic Modelling
} Jing Yang Tan ${ }^{\mathrm{a}}$, Fabrizio Bonatesta ${ }^{\mathrm{b}}$, Hoon Kiat $\mathrm{Ng}^{\mathrm{a},{ }^{*},}$, Suyin $\mathrm{Gan}^{\mathrm{c}}$

a Department of Mechanical, Materials and Manufacturing Engineering, University of Nottingham Malaysia, Jalan Broga, 43500 Semenyih, Selangor Darul Ehsan, Malaysia

b Department of Mechanical Engineering and Mathematical Sciences, Oxford Brookes University, Wheatley Campus, Oxford OX33 1HX, United Kingdom

c Department of Chemical and Environmental Engineering, University of Nottingham Malaysia, Jalan Broga, 43500 Semenyih, Selangor Darul Ehsan, Malaysia

* Corresponding author. Tel.: +60 3 89248161; fax: +60 389248017.

E-mail address: hoonkiat.ng@nottingham.edu.my (H.K. Ng).

\begin{abstract}
Despite improvements in thermal efficiency and fuel economy, gasoline direct injection (GDI) engines have been identified as a prominent source of ultra-fine particulate matter (PM) in the atmosphere. Adverse impacts caused by PM on the environment and public health motivate the need to deepen the understanding of PM emissions from GDI engines. Hence, an integrated modelling approach is formulated to investigate PM processes in a wall-guided GDI engine by bridging the gap between computational fluid dynamics (CFD) and chemical kinetics. Serving as the gasoline surrogate, a reduced and validated toluene reference mechanism is selected. Spray, turbulence, fuel impingement, liquid film, spark ignition, combustion and PM emissions are modelled by a complete set of CFD sub-models. The dynamic multi-zone partitioning is introduced within the CFD framework for computational expenditure while soot modelling is addressed through the sectional method. In-cylinder pressures, number density and mass density of PM are reproduced across engine speeds of 1600-3000 rpm and loads with torques of 60-120 N m. Under a homogenous stoichiometric mode, dominant formation mechanisms of PM are highlighted as the emergence of fuel-rich regions and the presence of residual liquid fuel droplets at the spark timing. The former is attributed to film stripping and evaporation due to spray-wall interactions while the latter stems from poor droplet vaporisation from fuel injected, rebounded, splashed and/or stripped from the liquid film. Optimised control strategies for GDI engine operations should target to minimise these sources for effective PM abatement.
\end{abstract}




\section{Keywords}

GDI engine; CFD modelling; Multi-zone partitioning; Particulate matter; Soot

\section{Abbreviations}

A4

$\mathrm{BDC}$

$\mathrm{C}_{2} \mathrm{H}_{2}$

CAD

CFD

$\mathrm{DMZ}$

EOI

EVO

GDI

HACARC

IVC

IVO

KH-RT

$\mathrm{OH}$

$\mathrm{PAH}$

PFI

PM

SI

SOI

TDC

TRF
Pyrene

Bottom dead centre

Acetylene

Crank angle degree

Computational fluid dynamics

Dynamic multi-zone

End of injection

Exhaust valve opening

Gasoline direct injection

Hydrogen-abstraction-carbon-addition ring closure

Intake valve closing

Intake valve opening

Kelvin-Helmholtz-Rayleigh-Taylor

Hydroxyl

Polycyclic aromatic hydrocarbons

Port fuel injection

Particulate matter

Spark ignition

Start of injection

Top dead centre

Toluene reference fuel

\section{Introduction}

As a promising substitute to the conventional port fuel injection (PFI) engines, gasoline direct injection (GDI) engines are gaining popularity among the automotive manufacturers. Owing to removal of throttling mechanism and precise control of air-fuel ratio, GDI engines offer minimised pumping loss, higher compression ratio, reduced knock tendency and improved 
transient response ${ }^{1}$. GDI engines operate in stratified, homogeneous lean and homogeneous stoichiometric modes depending on the speed-load points ${ }^{2}$. In a stratified lean operation, late injection of fuel during compression stroke maximises the fuel economy due to reduced throttling loss and lower heat loss ${ }^{1}$. Meanwhile, homogeneous operation which requires early fuel injection strategy during intake stroke covers the majority of the engine operating map, particularly at high-speed and high-load conditions.

Continuing research works have, relatively recently, identified GDI engines as a prominent source of anthropogenic ultra-fine particulate matter (PM) in the atmosphere. It was demonstrated that both number and mass emissions of PM from GDI engines are higher than those of conventional PFI engines and diesel engines fitted with diesel particulate filters ${ }^{3,4}$. Analysis of exhaust emissions from light-duty GDI vehicles reveals that the composition of PM is dominated by elemental carbon ${ }^{5,6}$ (up to $92 \%$ of total carbon content on average ${ }^{7}$ ) which is more commonly known as soot. With diameters less than $100 \mathrm{~nm}$ typically, the airborne particles pose elevated health risks such as asthma, adverse cardiovascular and neurodegenerative effects ${ }^{8-10}$. The newer Euro 6 standard tightens the mass limit to $4.5 \mathrm{mg} / \mathrm{km}$ and restricts the number emission to $6 \times 10^{11} / \mathrm{km}$ whereby the limits are expected to take full effect by $2020^{11}$. To facilitate the quest for strategy optimisation in PM mitigation, fundamental knowledge on PM processes within the GDI engine configurations is both imperative and timely.

Advanced optical techniques are employed to visualise the combustion and emission processes in GDI engines. Concurrently, sampling and measurement systems are continually upgraded to provide detailed information on particle size distribution function and chemical composition of engine-out exhausts. Many experimental studies ${ }^{12-14}$ highlighted that the vast majority of soot particles $(>80 \%)$ falls in the diameter range of $10-100 \mathrm{~nm}$ whereas above $50 \%$ is emitted in nucleation mode with diameter below $50 \mathrm{~nm}$. However, quantification of PM data downstream at the tailpipe lacks informative insights on in-cylinder events contributing to the formation mechanisms at the rudimental level. To this end, numerical modelling through computational fluid dynamics (CFD) serves as a robust and cost-effective predictive tool to complement the experimental findings.

Within the context, significant works in calibrating and developing CFD models have been performed to properly characterise spray formation, mixture preparation and combustion for GDI engines. In particular, current combustion models widely adopted for GDI system (e.g. 
extended coherent flame model ${ }^{15}$ and its variants ${ }^{16-18}$ ) mainly rely on pre-generated library tables from reaction kinetics of transportation fuels in lieu of direct computation of fuel chemistry ${ }^{19}$. Thus, computational speedup provided by the former storage-retrieval approach comes at the expense of accuracy of the chemistry effects. The main drawback is that mass exchange between solid and gaseous phases cannot be accounted for in the tabulated strategy 20 .

On the other hand, modelling studies on PM emissions from GDI engines are scarce as compared to those conducted on diesel engines as a result of the relatively recently discovered association of the former to PM. Etheridge et al. ${ }^{21}$ and Wang et al. ${ }^{22}$ solved population balance equations of soot particles using the Monte Carlo methods. The engine model was, however, spatially zero-dimensional. Due to the simplicity, two-step ${ }^{23}$ and three-step ${ }^{24}$ soot models are applied to predict soot formation but major phases such as surface growth and coagulation are not included. There are only a few modelling studies which adopted the method of moments 25,26 to address aerosol dynamics and coupled chemical kinetics of fuel ${ }^{25,27}$ to the soot models within GDI engine configurations.

Set against this background, the present study aims to acquire in-depth insights on the ultrafine PM processes in GDI engines through integrated CFD-chemical kinetic modelling. To represent gasoline fuel, an existing reaction mechanism of toluene reference fuel (TRF) is identified based on its applicability under GDI engine operations. The chemical kinetics is then incorporated to a set of CFD sub-models in describing spray, mixture formation, combustion and emissions within a wall-guided GDI engine. This integrated approach results in intensive reactive flow calculations as the computational cost scales cubically with the number of species ${ }^{28}$. Thus, a multi-zone partitioning strategy is utilised to expedite the computations and render the approach feasible in engine simulations.

To model soot processes, the sectional method is adopted as a detailed framework in resolving aerosol dynamics of the ultra-fine particles. The simulation results are validated against the experimental measurements of in-cylinder pressures, number density and mass density of soot. The integrated approach is also extended across varying engine speeds (1600-3000 rpm) and loads (torques of 60-120 N m) to explicate their effects on PM emissions. The knowledge on PM formation mechanisms is then drawn conceptually for the wall-guided GDI engine operating under the homogenous stoichiometric mode. 


\section{Integrated CFD-Chemical Kinetic Modelling for GDI Engines}

\subsection{Experimental Setup of GDI Engine Test Bed}

The test engine is a turbocharged and intercooled wall-guided GDI engine of Euro 4 standard while the unleaded fuel employed was a pump-grade reference gasoline. Table 1 lists down the important fuel properties and technical specifications of the engine. Installed on a laboratory test bed, the four-stroke and four-cylinder engine was controlled by a Schenck W150 eddycurrent dynamometer via Sierra-CP Engineering CADET automated control and data acquisition system. The engine control unit optimised spark ignition (SI) timing in an openloop process for maximum thermal efficiency and controlled fuel injection strategy to achieve homogeneous stoichiometric combustion.

Table 1 Fuel properties of the reference gasoline and technical specifications of the GDI test engine.

\begin{tabular}{ll}
\hline Fuel property & Value \\
\hline Research octane number & 95 \\
Motor octane number & 85 \\
Hydrogen/carbon ratio & 1.89 \\
Density at $15^{\circ} \mathrm{C}\left(\mathrm{kg} / \mathrm{m}^{3}\right)$ & $743-756$ \\
Aromatics $($ volume $\%)$ & $29-35$ \\
\hline Engine specification & Value/Description \\
\hline Cylinder displacement $\left(\mathrm{cm}^{3}\right)$ & 399.5 \\
Bore (mm) & 77 \\
Stroke (mm) & 85.8 \\
Compression ratio & 10.5 \\
Connecting rod length $(\mathrm{mm})$ & 138.4 \\
Combustion chamber & 4 -valve, central spark plug, pent-roof design \\
Maximum engine speed $(\mathrm{rpm})$ & 6000 \\
Maximum rated torque $(\mathrm{N} \mathrm{m})$ & 240 \\
Number of nozzle holes & 7 (circumferential arrangement) \\
Diameter of nozzle hole $(\mathrm{mm})$ & 0.165 \\
\hline & \\
\hline
\end{tabular}


Engine testing was carried out under fully-warm and steady-state operating conditions. Five operating cases under investigation covered a portion of the part-load running regime to represent typical urban and cruise driving situations. Engine speeds were varied between 1600 rpm, $2300 \mathrm{rpm}$ and $3000 \mathrm{rpm}$ at a fixed load. A variation in engine load at a constant speed was achieved by introducing three levels of torque in the range of $60 \mathrm{~N} \mathrm{~m}$ to $120 \mathrm{~N}$ m with an increment of $30 \mathrm{~N} \mathrm{~m}$. For brevity, the five part-load operating conditions are denoted by the 'speed (in rpm)-torque (in $\mathrm{N} \mathrm{m}$ )' convention hereafter. To enable the homogeneous combustion mode, fuel injections for all the cases took place during the intake stroke when the piston moved from the top dead centre (TDC) to the bottom dead centre (BDC). Fuel injection, SI, intake and exhaust valve timings are illustrated graphically in Figure 1. The experimental configurations of and related measurements from the engine test bed were provided by Oxford Brookes University. Detailed information on engine operations and data collection procedures has been elaborated elsewhere ${ }^{29,30}$. 
(a) $1600-90$

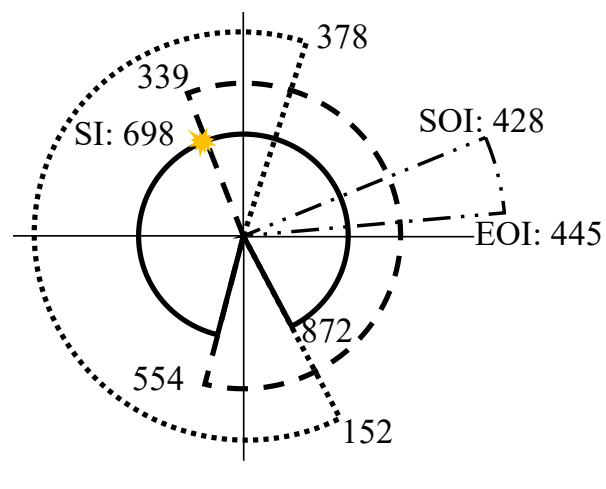

$\mathrm{BDC}$

(c) $2300-90$

$$
\text { TDC: } 0
$$

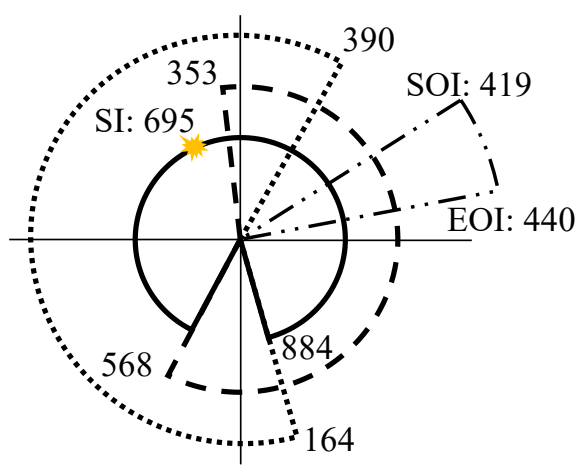

BDC

(e) $3000-90 \quad \rightarrow$ TDC: 0

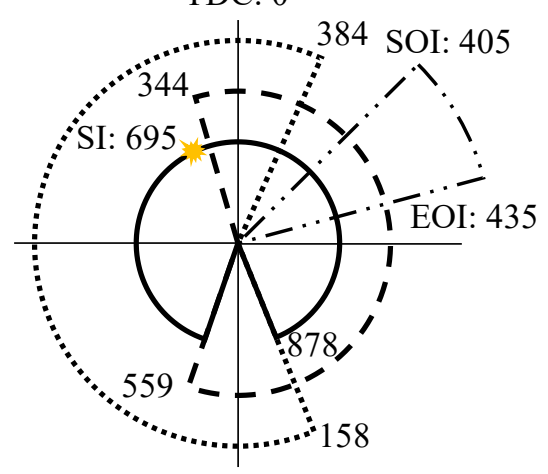

$\mathrm{BDC}$ (b) $2300-60 \underset{\mathrm{TDC}: 0}{\rightarrow}$

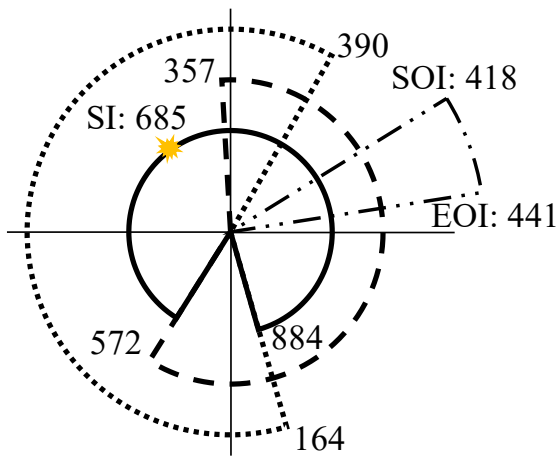

$\mathrm{BDC}$

(d) $2300-120 \underset{\text { TDC: } 0}{\rightarrow}$
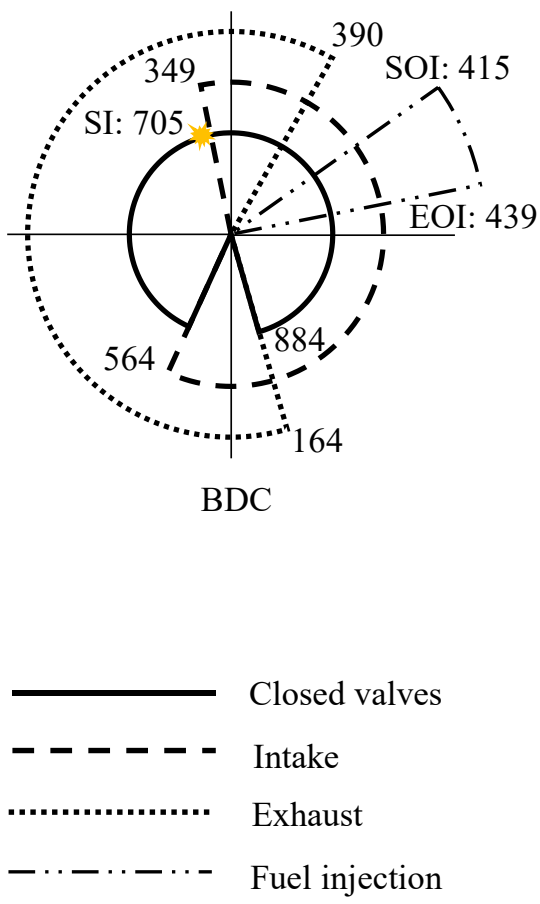

SOI: Start of injection

EOI: End of injection

Figure 1 Valve timing diagrams including fuel injection and ignition events for the five partload operating conditions.

\subsection{TRF Reaction Mechanism}

The TRF reaction mechanism employed in the present study was developed by An et al. ${ }^{31}$ which comprises 85 species and 232 reactions. The mechanism was primarily based on the 
work by Pang et al. ${ }^{32}$ with the chemistry of polycyclic aromatic hydrocarbons (PAH) derived from Appel et al.'s ${ }^{33}$ and Raj et al.'s ${ }^{34}$ mechanisms. The validation targets included ignition delay of gasoline surrogates under test conditions of shock tube and laminar flame speed of a commercial gasoline. Additionally, speciation profiles of fuel, oxygen, major products $(\mathrm{CO}$, $\left.\mathrm{CO}_{2}\right)$, intermediates $\left(\mathrm{C}_{2} \mathrm{H}_{2}, \mathrm{C}_{2} \mathrm{H}_{4}, \mathrm{C}_{3} \mathrm{H}_{4}, \mathrm{C}_{3} \mathrm{H}_{6}\right)$ and $\mathrm{PAH}$ species (A1, A2, A3, A4) under rich premixed flames of iso-octane and n-heptane were reasonably reproduced by the mechanism.

\subsection{Numerical Formulation}

The computational domain of the wall-guided GDI engine consists of intake and exhaust ports, valves and combustion chamber with the piston. Half of the engine geometry is modelled due to symmetry of the pent-roof design of combustion chamber and the fuel injector nozzle. The present computational grid features a typical cell size of $1 \mathrm{~mm}$ with local refinements of approximately $0.5 \mathrm{~mm}$ in the vicinity of valve seat and spark plug regions as shown in Figure 2. The resulting optimised mesh totals up to 212272 cells when the piston is at TDC and 365720 cells when the piston is at BDC. To improve mesh quality and reduce the effect of grid topology on the computations, regular hexahedral cells were primarily utilised whenever applicable.

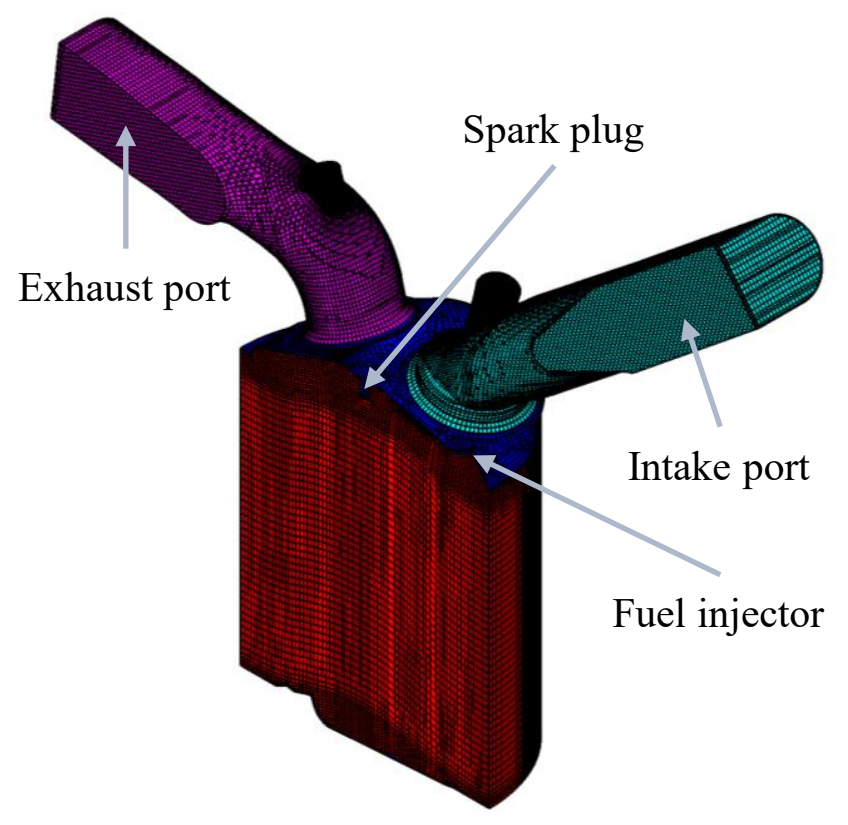

Figure 2 Computational grid of the GDI test engine model with intake port, exhaust port, spark plug and fuel injector indicated.

The numerical simulations begin at 40 crank angle degree (CAD) before TDC during the exhaust stroke of the previous cycle (i.e. $320 \mathrm{CAD}$ ) and complete at EVO during the power stroke of the current modelled cycle (i.e. 884 CAD for 2300-90). The modelling period hence 
covers all the major in-cylinder events including gas exchange, spray, mixture preparation, ignition, combustion and emissions. Sufficient temporal resolution to capture the transient engine processes is achieved with the general time-step size of 0.1 CAD. It is noteworthy to highlight that more refined steps (0.01 CAD) are defined for valve opening and closing events, fuel injection and combustion processes to account for more rapid flow changes. To ensure the accuracy of numerical results, the mean Courant numbers at all computational cells are monitored to be always below unity throughout the modelling.

Initial and boundary conditions of the cylinder, ports and valves are set in terms of their respective pressures and temperatures. The resulting algebraic finite-volume equations are solved implicitly through the PISO algorithm. The method implements a predictor-corrector strategy enabled by the use of operator splitting to temporarily decouple the flow equations and solve them sequentially. Three-dimensional CFD modelling of GDI engine operations is performed using STAR-CD 4.30 with a hyper-threaded Intel Xeon hexa-core processor at a running speed of $3.30 \mathrm{GHz}$ and a random-access memory of $16 \mathrm{~GB}$.

\subsubsection{CFD Sub-models}

The in-cylinder turbulence is described by re-normalisation group $\mathrm{k}-\varepsilon$ model ${ }^{35}$ to account for the effect of mean flow distortion on turbulence ${ }^{36}$. Initial droplet size distribution of the fuel is expressed mathematically as the Rosin-Rammler distribution function. As corroborated in spray modelling studies of GDI engines ${ }^{37-39}$, the Kelvin-Helmholtz-Rayleigh-Taylor (KH-RT) model ${ }^{40}$ is selected to describe the breakup of fuel droplets as a result of interfacial forces. Near-wall treatments to model in-cylinder heat transfer are described by the wall function proposed by Angelberger ${ }^{41}$. Fuel impingement due to spray-wall interactions is governed by the Bai-ONERA model ${ }^{42,43}$ to predict the outcome of a droplet impact as deposition/spread, splashing or rebound. The numerical model describing the dynamic behaviours of liquid films follows the Eulerian formulation ${ }^{44}$ in which film detachment occurs by surface and/or edge stripping ${ }^{45}$. Upon ignition, the spark is treated numerically by specifying the initiation position, ignition temperature, spark kernel size and duration. Flame propagation factor is calibrated to emulate the actual flame front propagation and development within the cylinder. 


\subsubsection{Detailed Chemistry Model}

Designed to incorporate reaction kinetics in engine simulations, the Detailed Chemistry model efficiently solves transport equations for all chemical species based on the TRF mechanism described in Section 2.2. The transport equations for species mass fractions are

$$
\begin{aligned}
& \frac{\partial}{\partial t}\left(\rho Y_{i}\right)+\frac{\partial}{\partial x_{j}}(\rho u_{j} Y_{i}-\underbrace{F_{i, j}}_{\begin{array}{c}
\text { Diffusion flux } \\
\text { component }
\end{array}})=S_{i} \\
& F_{i, j}=\frac{\mu_{t}}{S_{i}} \frac{\partial Y_{i}}{\partial x_{j}}+\rho D_{i m} \frac{\partial Y_{i}}{\partial x_{j}}+\frac{D_{i}^{T}}{T} \frac{\partial T}{\partial x_{j}}
\end{aligned}
$$

where $\mathrm{S}_{\mathrm{i}}$ is the source term due to chemical reactions, $\mathrm{Sc}_{\mathrm{i}}$ is the $\mathrm{Schmidt}$ number for species $\mathrm{i}$, $D_{i m}$ is the molecular diffusivity of species $i$ in the mixture while $D_{i}^{T}$ is the thermal diffusion coefficient of species i.

To expedite the computations, the dynamic multi-zone (DMZ) partitioning method ${ }^{46}$ is adopted to create groups of computational cells sharing a similar thermo-chemical state. With this approach, Equation (1) is solved for each group instead of for each cell to warrant a substantial saving in the associated computational time. The overview of the DMZ method within the Detailed Chemistry model is illustrated in Figure 3.

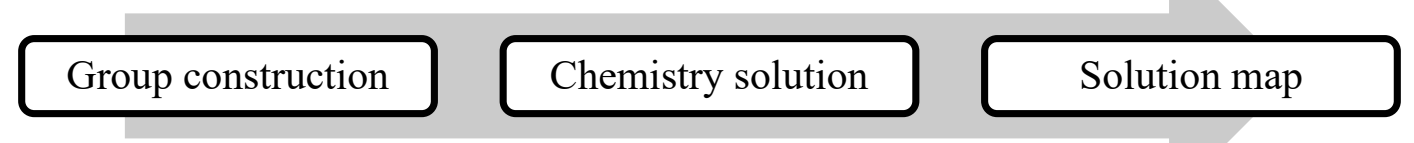

Figure 3 Sequential steps of the DMZ method within the Detailed Chemistry model.

Groups are constructed by clustering cells that are in similar thermal and chemical states described by certain cell-averaged characteristic quantities. As an improvement to the earlier works ${ }^{46,47}$, four flow variables pertinent to GDI combustion systems are proposed in the present study as the grouping criteria. They are temperature (representing the combustion progress), mixture fraction (representing the mixing process), enthalpy (representing the energy level) and mass fraction of hydrogen atom (capturing the SI process). 
Subsequently, the calculated mean mass fractions of a group can be advanced in time by solving Equation (1) in the form

$$
\rho_{\mathrm{i}, \mathrm{g}} \frac{\partial \mathrm{Y}_{\mathrm{i}, \mathrm{g}}}{\partial \mathrm{t}}=\omega_{\mathrm{i}, \mathrm{g}}
$$

where $\omega_{i, g}$ is the reaction rate of species $i$ in group $g$, evaluated on the basis of group mean quantities. After the chemistry solution is obtained for each group, the mean reaction rate of all species in the group can be deduced. Through solution mapping, the mass fractions of all species in a cell at the $(n+1)$-th time-step can be calculated as follows:

$$
\begin{aligned}
& Y_{i}{ }^{n+1}=Y_{i}{ }^{n}+\delta t \cdot \overline{\omega_{i, g}} \\
& \overline{\omega_{i, g}}=\frac{Y_{i, g}{ }^{n+1}-Y_{i, g}{ }^{n}}{\delta t}
\end{aligned}
$$

The mapping algorithm makes sure that the mass fractions of species are bounded and conservations of mass and atoms are maintained accordingly.

\subsubsection{Sectional Method}

Soot particles are treated as solids and modelled as a distinct dispersed phase which interacts with the gaseous phase within the turbulent reactive flow The sectional method ${ }^{48}$ involves a volume-based discretisation of particle sizes with the conservations of number density and mass. The selection of sections corresponds to ultra-fine soot particles with the diameter range of 1.05-106 nm with the volume of PAH treated as $4 \times 10^{-28} \mathrm{~m}^{3}$ for pyrene (A4). The source term is the resulting net contribution from particle inception, PAH condensation, surface growth, oxidation and coagulation of soot particles. The respective source term is computed on the fly at each time-step from the mass fractions of relevant species and temperatures derived from the Detailed Chemistry model.

In particle inception, the first solid particle from the gas phase is formed through the collision between two PAH molecules. The nucleation of soot particles from PAH is also supported by transmission electron microscopy ${ }^{49}$ and molecular dynamics simulations ${ }^{50}$. Within the context, A4 is selected as the soot precursor species. The inception rate is derived from the Smoluchowski equation ${ }^{51}$ as 


$$
\dot{\mathrm{Q}}_{\mathrm{i}, \mathrm{pi}}=2 \mathrm{~V}_{\mathrm{PAH}} \beta_{\mathrm{pi}}\left(\mathrm{V}_{\mathrm{PAH}}\right) \mathrm{N}_{\mathrm{PAH}}^{2}
$$

where $\beta$ is the collisional coefficient and $\mathrm{N}_{\mathrm{PAH}}$ is the number density of PAH. It is noted that the inception is only active in the first section while the source term is zero for the remaining sections.

The collisions between PAH and soot particles give rise to PAH condensation on the particle surfaces which increases particle sizes. The rate of condensation is governed by

$$
\dot{\mathrm{Q}}_{\mathrm{i}, \text { cond }}=\mathrm{V}_{\text {PAH }} \mathrm{N}_{\mathrm{PAH}} \int_{\mathrm{V}_{\mathrm{i}, \text { min }}}^{\mathrm{V}_{\mathrm{i} \text { max }}} \beta_{\text {cond }}\left(\mathrm{V}_{\mathrm{PAH}}, \mathrm{V}\right) \mathrm{n}(\mathrm{V}) \mathrm{dV}
$$

At the same time, coagulation characterises the inter-particle collisions to form larger soot particles whereby the rate is computed as

$$
\begin{aligned}
& \dot{\mathrm{Q}}_{\mathrm{i}, \text { coag }}=\sum_{\mathrm{V}_{\mathrm{i}, \text { min }}<\left(\mathrm{V}_{\mathrm{k}}+\mathrm{V}_{\mathrm{j}}\right)<\mathrm{V}_{\mathrm{i}, \text { max }}}\left(\mathrm{V}_{\mathrm{k}}+\mathrm{V}_{\mathrm{j}}\right) \mathrm{N}_{\mathrm{k}} \mathrm{N}_{\mathrm{j}} \beta_{\text {coag }}\left(\mathrm{V}_{\mathrm{k}}, \mathrm{V}_{\mathrm{j}}\right) \\
& +\sum_{\left(\mathrm{V}_{\mathrm{k}}+\mathrm{V}_{\mathrm{j}}\right)<\mathrm{V}_{\mathrm{i}, \max }} \mathrm{V}_{\mathrm{k}} \mathrm{N}_{\mathrm{k}} \mathrm{N}_{\mathrm{i}} \beta_{\text {coag }}\left(\mathrm{V}_{\mathrm{k}}, \mathrm{V}_{\mathrm{i}}\right)-\mathrm{V}_{\mathrm{i}} \mathrm{N}_{\mathrm{i}} \sum_{\left(\mathrm{V}_{\mathrm{k}}+\mathrm{V}_{\mathrm{j}}\right)>\mathrm{V}_{\mathrm{i}, \max }} \mathrm{N}_{\mathrm{j}} \beta_{\text {coag }}\left(\mathrm{V}_{\mathrm{i}}, \mathrm{V}_{\mathrm{j}}\right) \\
& -2 \mathrm{~V}_{\mathrm{i}} \mathrm{N}_{\mathrm{i}} \mathrm{N}_{\mathrm{i}} \beta_{\text {coag }}\left(\mathrm{V}_{\mathrm{i}}, \mathrm{V}_{\mathrm{i}}\right)
\end{aligned}
$$

It is noted that coagulation involves the interactions of soot particles from different sections.

On the other hand, surface growth and oxidation depend on the reactions describing the surface chemistry of soot particles. Surface growth increases particle size through carbon addition from the gaseous phase. In contrast, oxidation involves taking carbon from soot particles by oxygen and $\mathrm{OH}$ radicals, thus diminishing the particle size. The present work adopted the hydrogenabstraction-carbon-addition ring closure (HACARC) mechanism developed by Mauss et al. ${ }^{52}$. The HACARC mechanism is a modified version of that initially proposed by Frenklach and Wang ${ }^{53}$ to take into account the effects of reaction reversibility.

The rates of surface growth and oxidation for each section i are determined from Equations (9) and (10), respectively.

$$
\dot{\mathrm{Q}}_{\mathrm{i}, \mathrm{sg}}=\alpha \mathrm{V}_{\mathrm{C}_{2}} \frac{3-\theta}{3}\left(\mathrm{k}_{\mathrm{d}}-\mathrm{k}_{\mathrm{rev}}\right)\left[\frac{3}{3+\theta} \mathrm{q}_{\mathrm{i}}\left(\mathrm{V}_{\mathrm{i}, \max }^{\frac{3+\theta}{3}} \mathrm{~V}_{\mathrm{i}, \min }{ }^{\frac{3+\theta}{3}}\right)+\frac{3}{\theta} \mathrm{q}_{\mathrm{i}}^{\mathrm{u}}\left(\mathrm{V}_{\mathrm{i}, \max ^{\frac{\theta}{3}}}-\mathrm{V}_{\mathrm{i}, \min ^{\frac{}{3}}}\right)\right]
$$




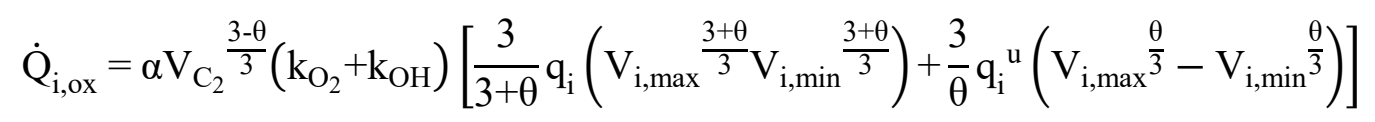

where $\theta$ is the fractional dimension of the soot particle and $\mathrm{k}$ is the reaction rate coefficient. The reference volume is chosen as $\mathrm{V}_{\mathrm{C}_{2}}$ so as to be consistent with the number of carbon atoms of the surface growth species, acetylene $\left(\mathrm{C}_{2} \mathrm{H}_{2}\right)$.

\subsection{Validations of GDI Engine Modelling}

Spray modelling is initially calibrated based on the experimental works carried out by Whelan ${ }^{54}$ using the similar 7-hole fuel injector in a static spray vessel with optical access. The vessel was filled with nitrogen and kept at ambient pressure of 1 bar. Via a downward-facing injector, the fuel was delivered at an injection pressure of 120 bar over a duration of $0.32 \mathrm{~ms}$. The KHRT model serves to replicate the experimental spray tip penetration length which is defined as the distance between the nozzle and the bulk of the spray containing $90 \%$ of the mass of fuel droplets. As seen in Figure 4, the excellent agreement between the measured and predicted spray penetration lengths with estimated deviations of $1 \mathrm{~mm}$ indicates that the transient process of spray development has been accurately modelled.

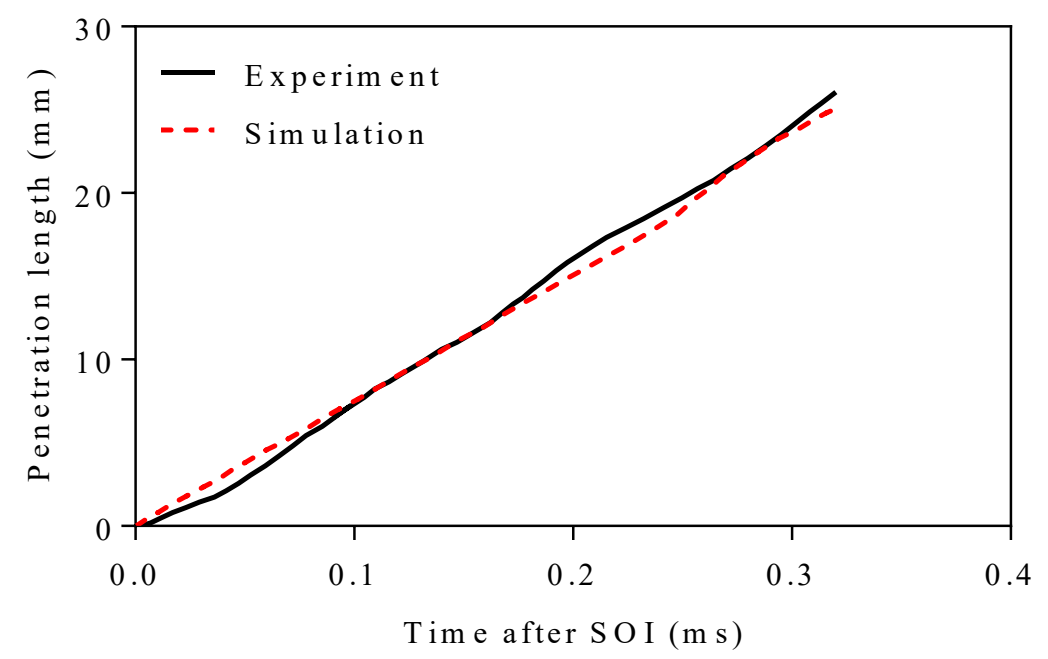

Figure 4 Measured and computed spray tip penetration length as a function of time after SOI at the injection pressure of 120 bar over the period of $0.32 \mathrm{~ms}$.

2300-90 is selected as the reference case to which the effects of an increase or a decrease in speed and load are benchmarked against and correlated to. Figure 5 displays both simulated and measured pressure curves for the reference case, together with the rate of pressure change. 
Good agreement in temporal development of in-cylinder pressures is seen, particularly at the peak value. In general, the computed pressures appear to be slightly higher with the maximum percentage difference approximated at 20\%. Figure 5(b) reveals that initiation of combustion is faster during the simulation as evidenced by the earlier rapid rise in rate of pressure change as compared to the experiment. The predicted trend then becomes consistent with the measured one after $735 \mathrm{CAD}$, signalling that the stage of late combustion is adequately captured.
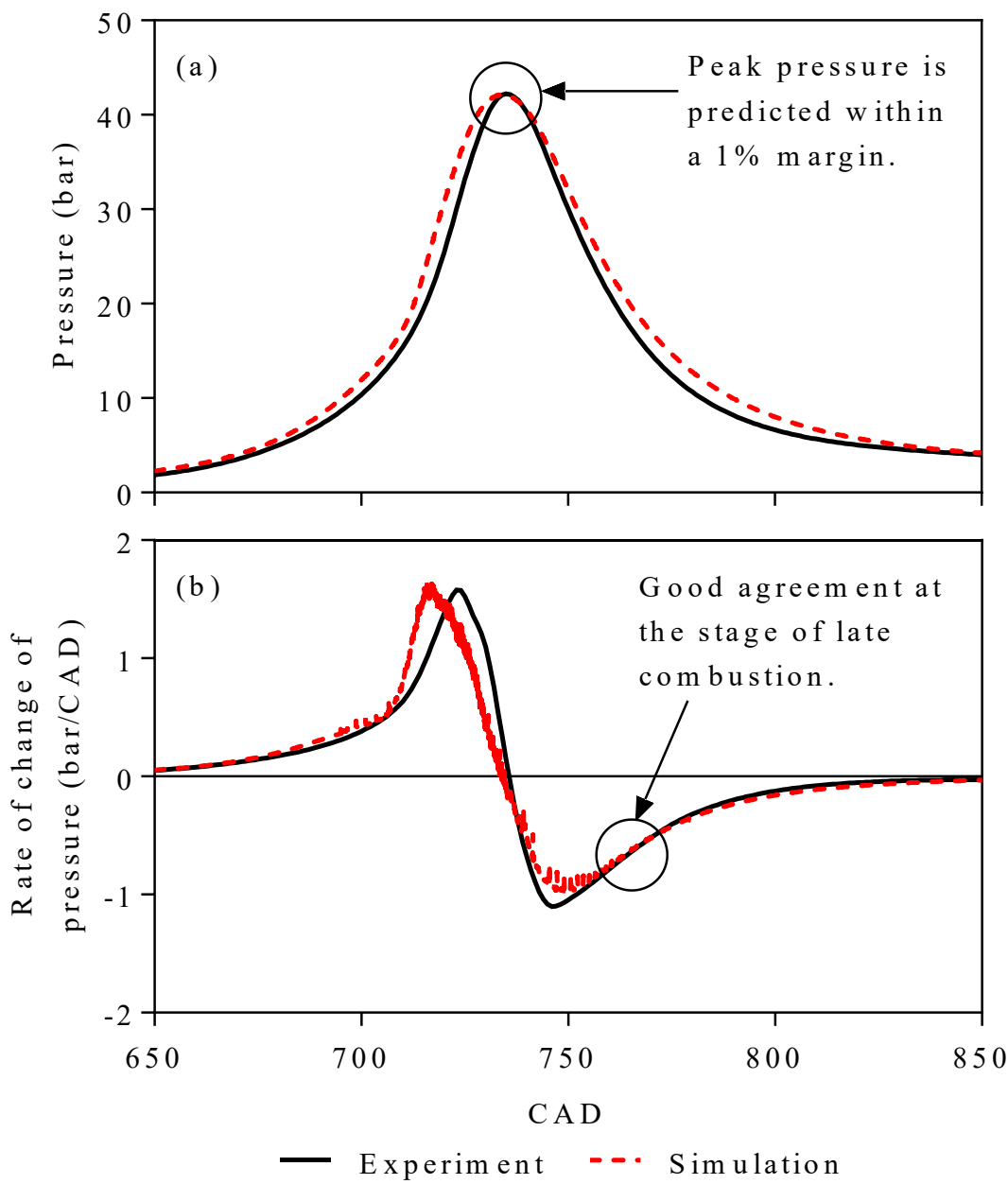

Figure 5 Measured and computed in-cylinder (a) pressure and (b) rate of change of pressure for the reference case.

Tailpipe measurements of PM are compared against the computed soot results from the sectional method at exhaust valve opening (EVO) under the commonly adopted assumption that soot particle physics and chemistry remain frozen beyond EVO. As illustrated in Figure 6, excellent agreement between the measured and computed number density of soot is observed at $\mathrm{EVO}$ with a percentage difference of $8 \%$. In contrast, mass density of soot is under-predicted 
roughly by a factor of two as compared to the measured value. The underestimation in soot mass is also observed in the few soot modelling studies with validations against experimental data in GDI engines ${ }^{26,55-57}$.

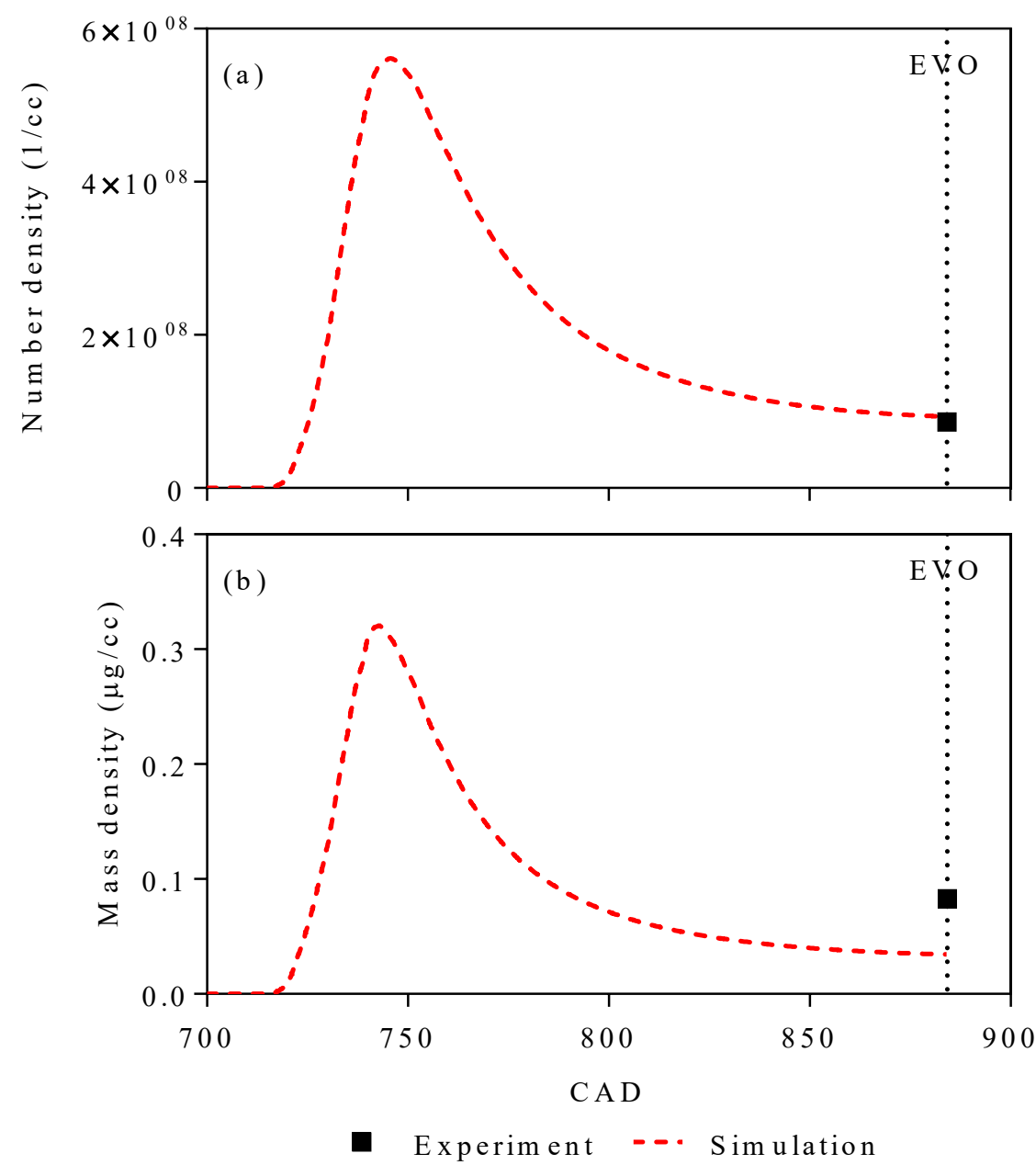

Figure 6 Computed (a) number density and (b) mass density of soot for the reference case along with the experimental data compared at EVO.

Engine-out PM are typically emitted in the form of fractal-like agglomerates. The lack of agglomeration modelling by treating soot particles as spherical primarily contributes to the underestimation of particle size and hence, the total mass. Moreover, the volatile components can be transformed into PM in solid phase through nucleation, condensation and adsorption as the exhaust is diluted and cooled at the measurement system ${ }^{56}$. Though to a lesser extent, PM experiences further condensation and coagulation past the valve into exhaust manifold after EVO. These jointly cause the increases in particle diameter and mass within the accumulation mode which are not modelled currently. The integrated CFD-chemical kinetic modelling 
approach is then extended across different speed-load operating points to explicate the effects of engine speed and load on PM emissions.

\section{Numerical Modelling of PM Processes across Speed-Load Domain}

\subsection{Effect of Engine Speed on PM Emissions}

At a constant load by fixing the engine torque at $90 \mathrm{~N} \mathrm{~m}$, the running speeds of $1600 \mathrm{rpm}, 2300$ rpm and $3000 \mathrm{rpm}$ represent the low-, medium- and high-speed conditions, respectively. The simulated pressure curves generally emulate the measured ones as depicted in Figure 7 with slight over-prediction at early combustion. The measured peak pressures are replicated with the maximum percentage deviation of $1.5 \%$ determined for 1600-90. From Figure 8, good agreement is observed between measured and computed number density of soot while lower values of mass density are calculated consistently. Nevertheless, replicated experimental trends in number density and mass density as portrayed by the close agreement in normalised results based on the reference case of 2300-90 suggest that the simulations capture the variation in PM emissions with respect to the change in engine speed properly.

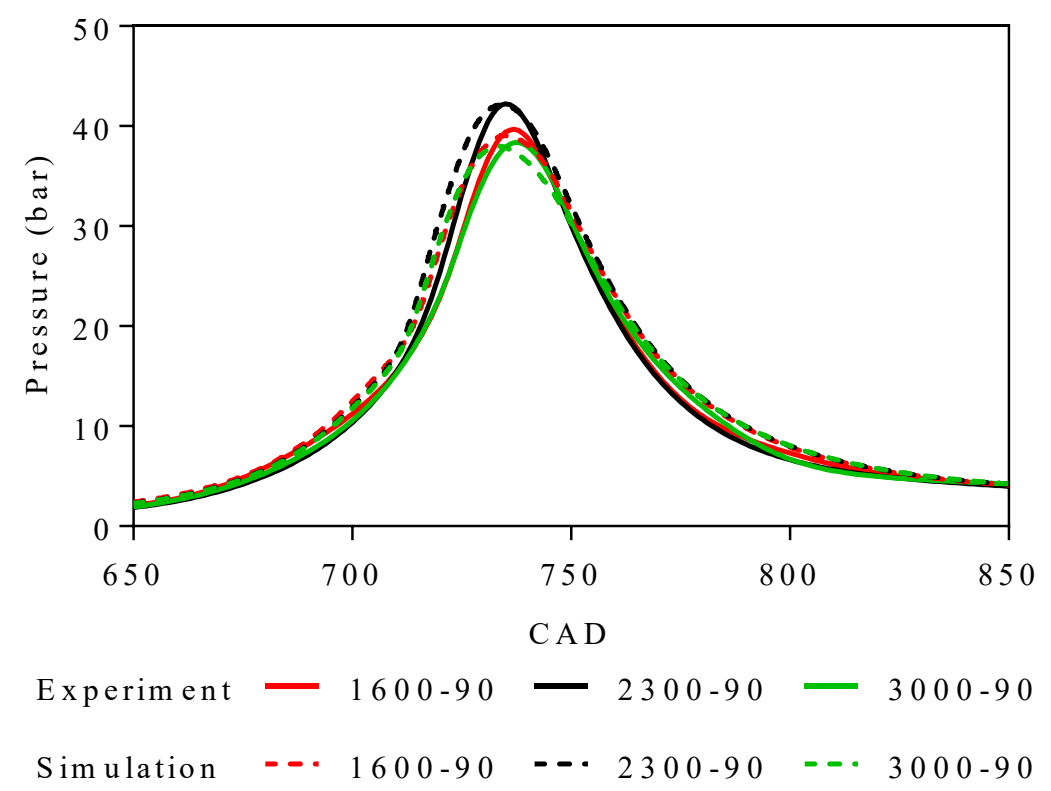

Figure 7 Measured and computed in-cylinder pressures for different engine speeds. 


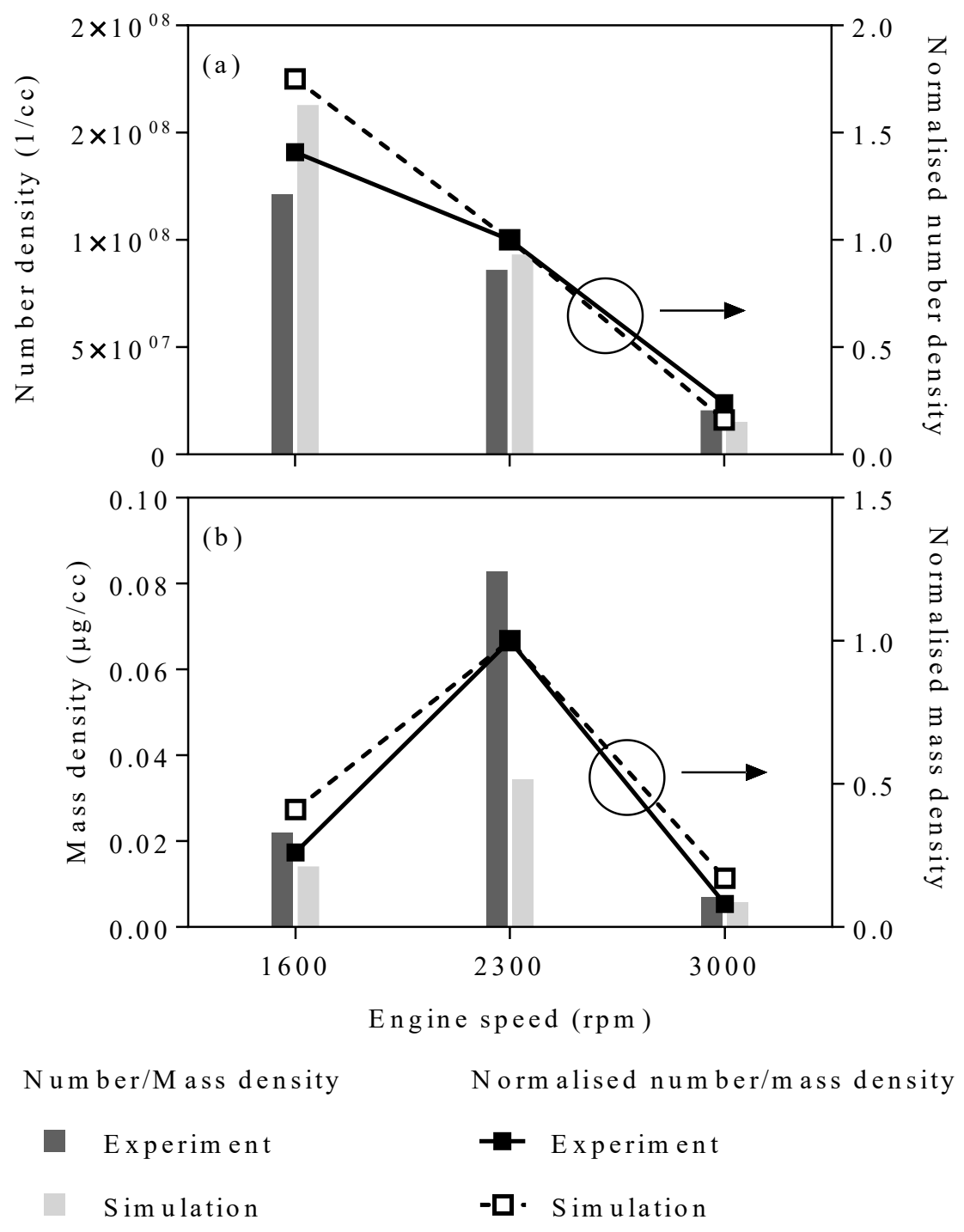

Figure 8 Measured and computed (a) number density and (b) mass density of soot and their normalised values based on the reference case for different engine speeds.

Engine speed influences the quality of spray and mixture preparation through induced flow intensity and time availability of the mixing process before SI. Higher flow velocity and shorter cycle time are associated with higher engine speed. As a result, higher tumble velocity and larger turbulence kinetic energy are generated as shown in Figure 9 due to faster piston movement. The tumble speeds gradually increase to their peak magnitudes after SOI with the highest rate of increase observed at 3000-90. The maximum turbulence kinetic energy after fuel injection is also higher by a factor of 2.4 and 3.9 at $2300 \mathrm{rpm}$ and $3000 \mathrm{rpm}$, respectively than that at $1600 \mathrm{rpm}$. As the piston approaches TDC, both tumble speed and turbulence kinetic energy diminish slowly due to the restriction of air motion across all engine speeds. 


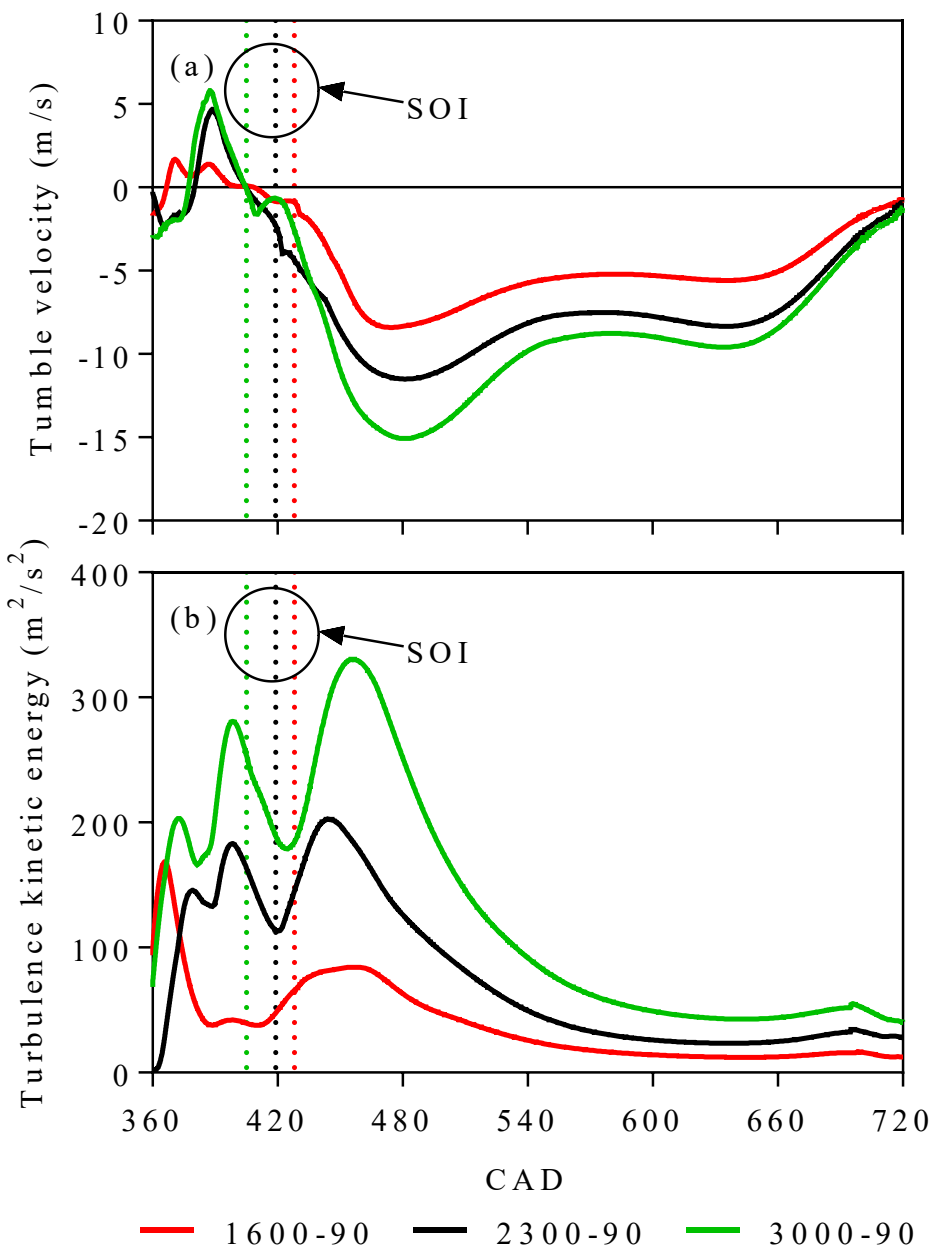

Figure 9 (a) Tumble velocity and (b) turbulence kinetic energy as a function of CAD for different engine speeds.

Therefore, increasing flow intensity benefits fuel spray and vaporisation characteristics to facilitate air-fuel mixing. As illustrated in Figure 10(a), the amount of liquid fuel droplets is significantly lower at higher engine speeds at their respective EOI. Also, enhanced flow field directs the fuel spray core towards the central domain with reduced impingement on the left wall peripheries. Since fuel vaporisation initiates earlier as the SOI is advanced correspondingly, the high-speed condition aids to attain a more uniform mixture distribution as depicted in Figure 10(b) with the fuel droplets being more scattered and atomised throughout the cylinder. At low speed of $1600 \mathrm{rpm}$, a large proportion of fuel droplets remains concentrated near the piston crown in liquid phase. 
(a) EOI

(i) $1600-90$

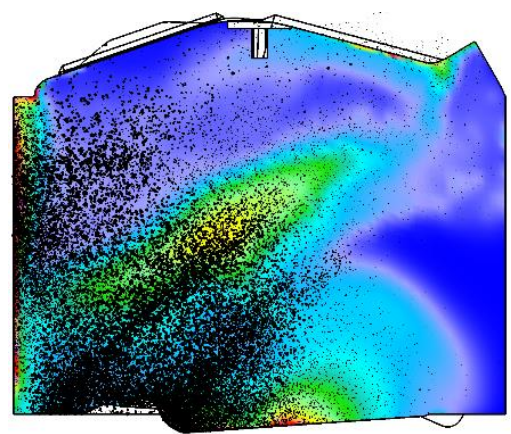

(b) 90 CAD BTDC

(i) $1600-90$

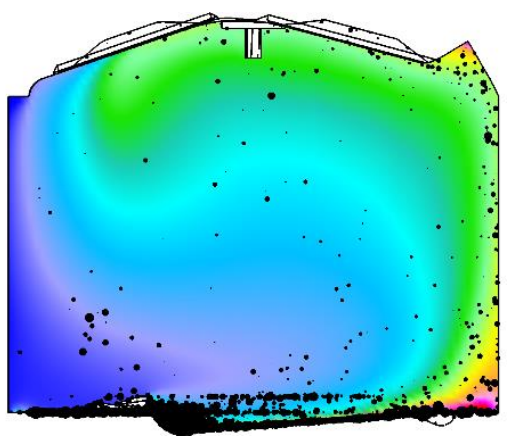

(ii) $2300-90$

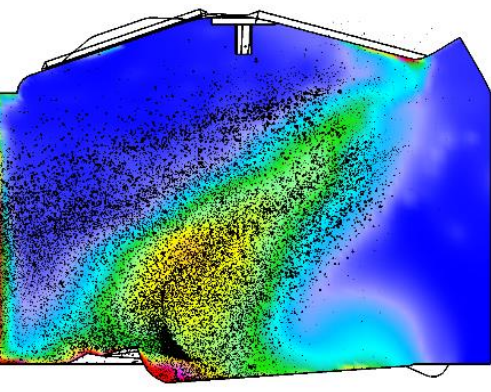

Equivalence ratio

0

(ii) $2300-90$

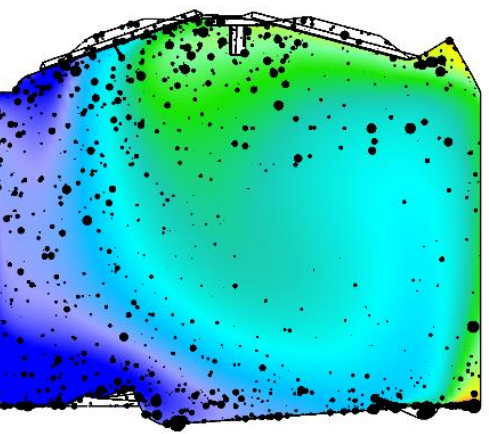

Equivalence ratio

6

0.5

(iii) $3000-90$

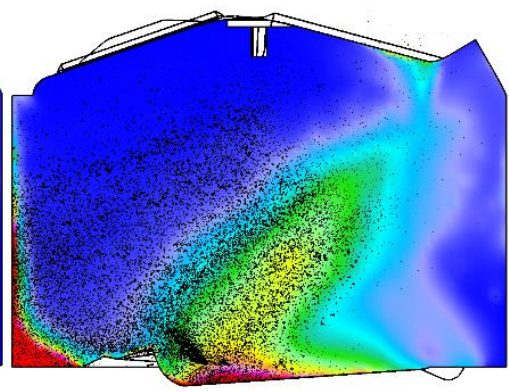

(iii) $3000-90$

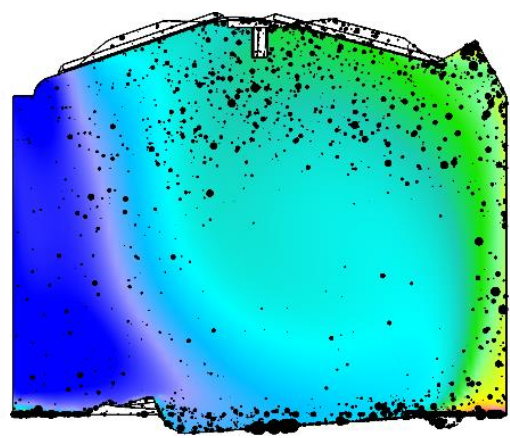

2.5

Figure 10 In-cylinder distributions of equivalence ratio superimposed with fuel droplets at (a) EOI and (b) 90 CAD before TDC during the compression stroke for engine speeds of (i) 1600 rpm, (ii) $2300 \mathrm{rpm}$ and (iii) $3000 \mathrm{rpm}$.

Fuel combustion behaviours including flame development and propagation heavily rely on the level of mixture homogeneity at SI timing. As depicted in Figure 11, increasing the engine speed has a positive influence on the overall uniformity of mixture distribution which in turn promotes homogeneous combustion. There are more fuel-rich pockets within the mixture under low-speed conditions of $1600 \mathrm{rpm}$ and $2300 \mathrm{rpm}$. The presence of such pockets is attributed to the weaker flow fields which fail to mix the fuel with air evenly before the spark initiation is activated. These fuel-rich regions are typically found near wall and piston surfaces due to the reduced air entrainment. 
(a) $1600-90$

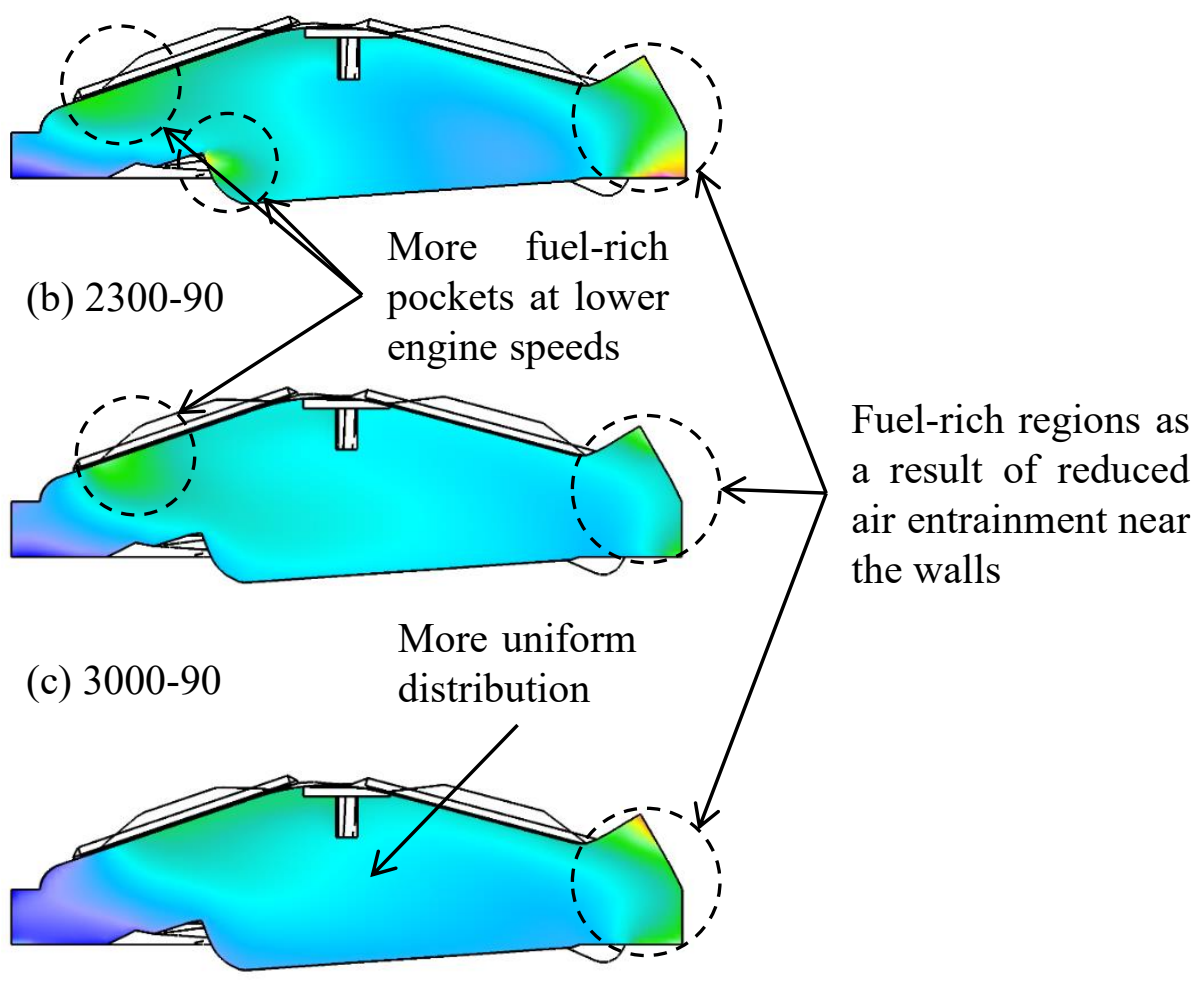

Equivalence ratio

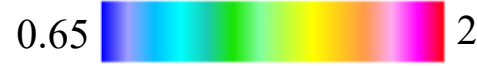

Figure 11 In-cylinder distributions of equivalence ratio at SI timing for engine speeds of (a) $1600 \mathrm{rpm}$, (b) $2300 \mathrm{rpm}$ and (c) $3000 \mathrm{rpm}$.

Upon SI, flame kernel formation and development is initiated from the position of spark plug. The $\mathrm{H}_{2} \mathrm{O}_{2}$ reaction loop proposed by Kuwahara and Ando ${ }^{58}$ is critical in the initiation of thermal ignition. The loop becomes active when hydroxyl $(\mathrm{OH})$ radical formation from the decomposition of $\mathrm{H}_{2} \mathrm{O}_{2}, \mathrm{H}_{2} \mathrm{O}_{2}(+\mathrm{M})=\mathrm{OH}+\mathrm{OH}(+\mathrm{M})$ dominates at about $950 \mathrm{~K}$. At the thermal-ignition range when the temperature is higher than $1500 \mathrm{~K}, \mathrm{OH}$ radicals are mainly contributed by the hydrogen-oxygen system, $\mathrm{H}+\mathrm{O}_{2}=\mathrm{O}+\mathrm{OH}$. The spatial contour of hightemperature core serves as a good indicator of flame front development and propagation as illustrated in Figure 12.

Increasing A4 concentration promotes molecular collisions between the precursors, thus giving rise to nascent soot particles. The onset of soot formation is captured at approximately 20-30 CAD after SI with visible soot clouds in Figure 12 across all engine speeds. Both $\mathrm{C}_{2} \mathrm{H}_{2}$ and A4 form around the high-temperature core at about 1000-2000 K. The similar ring-like structures 
were reported by An et al. ${ }^{59}$ with different spatial distributions due to varied orientation of the spark plug and direction of flame propagation. The concentration of A4 is significantly lower than that of $\mathrm{C}_{2} \mathrm{H}_{2}$ since it is the precursor species for particle inception. The distribution of soot cloud resembles those of $\mathrm{C}_{2} \mathrm{H}_{2}$ and $\mathrm{A} 4$, thus suggesting the consumption of the two species in soot formation.
(a) $1600-90$
(b) $2300-90$
(c) $3000-90$

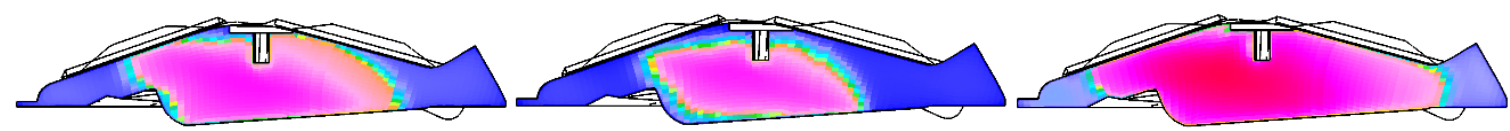

Temperature $(\mathrm{K})$

700 【 2800

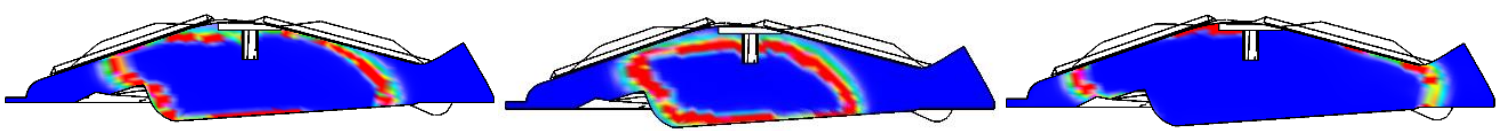

$$
\mathrm{C}_{2} \mathrm{H}_{2}
$$

$0 \llbracket 110^{-4}$

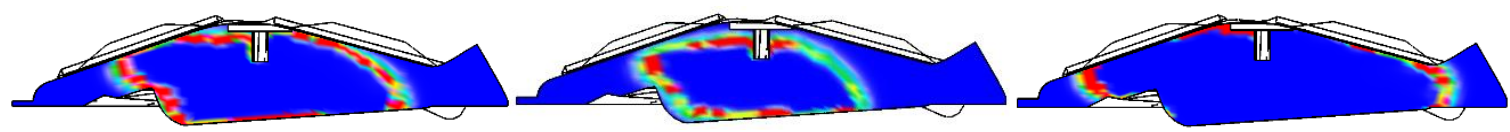

A4

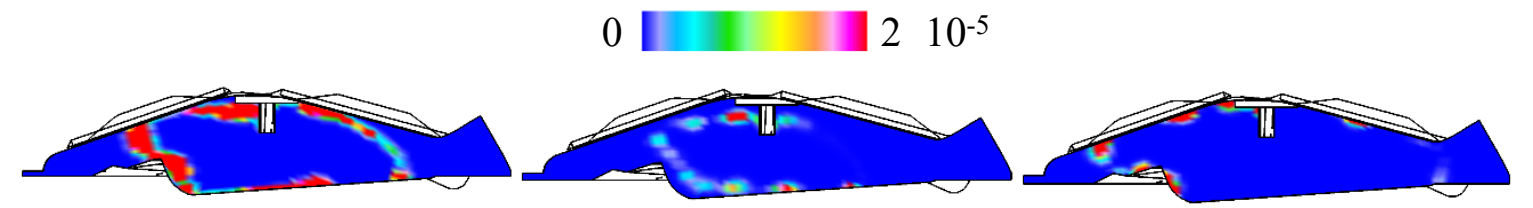

Number density $(1 / \mathrm{cc})$

1 ! $110^{9}$

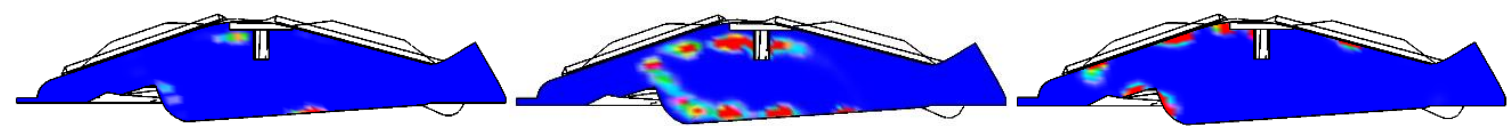

Mass density $(\mu \mathrm{g} / \mathrm{cc})$

0 ! 1

Figure 12 In-cylinder distributions of temperature, mass fractions of $\mathrm{C}_{2} \mathrm{H}_{2}$ and $\mathrm{A} 4$, number density and mass density of soot for engine speeds of (a) $1600 \mathrm{rpm}$, (b) $2300 \mathrm{rpm}$ and (c) 3000 rpm at the onset of soot formation.

Improved mixture homogeneity at higher engine speeds in Figure 11 is clearly manifested in the lowered amount of A4 and soot particles generated in Figure 12. At 1600-90, the abundance of A4 gives rise to the nucleation of high particle number at left cylinder domain and piston surface where fuel-rich regions are primarily observed in Figure 11(a). Homogeneous and rapid 
combustion at $3000 \mathrm{rpm}$ suppresses production of $\mathrm{C}_{2} \mathrm{H}_{2}$ and $\mathrm{A} 4$, hence restraining the soot formation. Moreover, shorter soot residence time at high engine speed limits further particle formation and growth. Higher mass density of soot at 2300-90 is partly attributed to increased surface growth from high availability of $\mathrm{C}_{2} \mathrm{H}_{2}$ and enhanced particle collision which promotes coagulation at higher engine speed.

During the late stage of combustion, with $\mathrm{C}_{2} \mathrm{H}_{2}$ and $\mathrm{A} 4$ consumed, soot oxidation becomes the dominant mechanism to decrease particle number and size, thus lowering the overall mass. As seen in Figure 13, the decline in soot number density across all engine speeds is associated directly to the high-temperature zones with copious $\mathrm{OH}$ radicals. Coupled with high mass fraction of $\mathrm{OH}$ radicals, the left-skewed high-temperature contour explains the higher soot concentration on the right side of cylinder. For 1600-90, significantly high soot particle number is observed at the right near-wall region. This can be attributed to reduced rate of soot oxidation due to the limited presence of $\mathrm{OH}$ radicals in the same region despite the high temperature. 
(a) $1600-90$

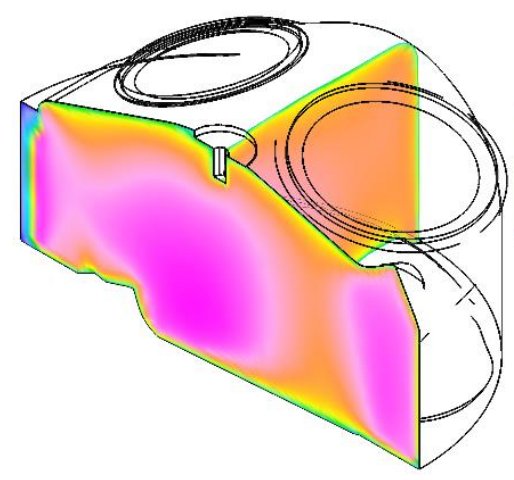

(b) $2300-90$

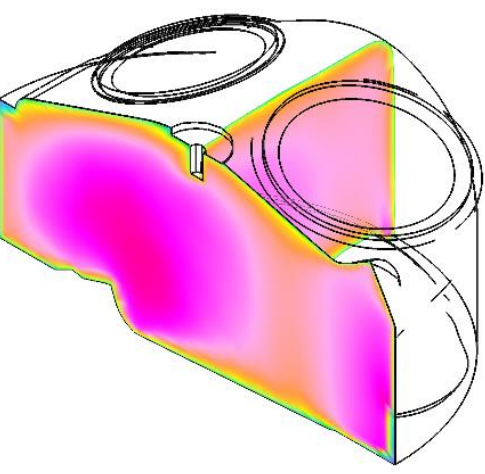

Temperature (K)

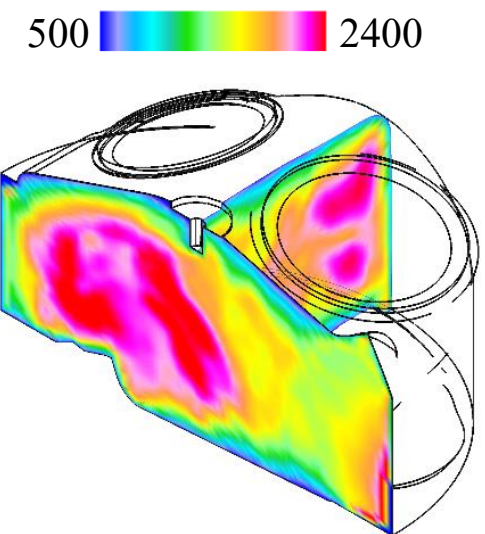

\section{$\mathrm{OH}$}
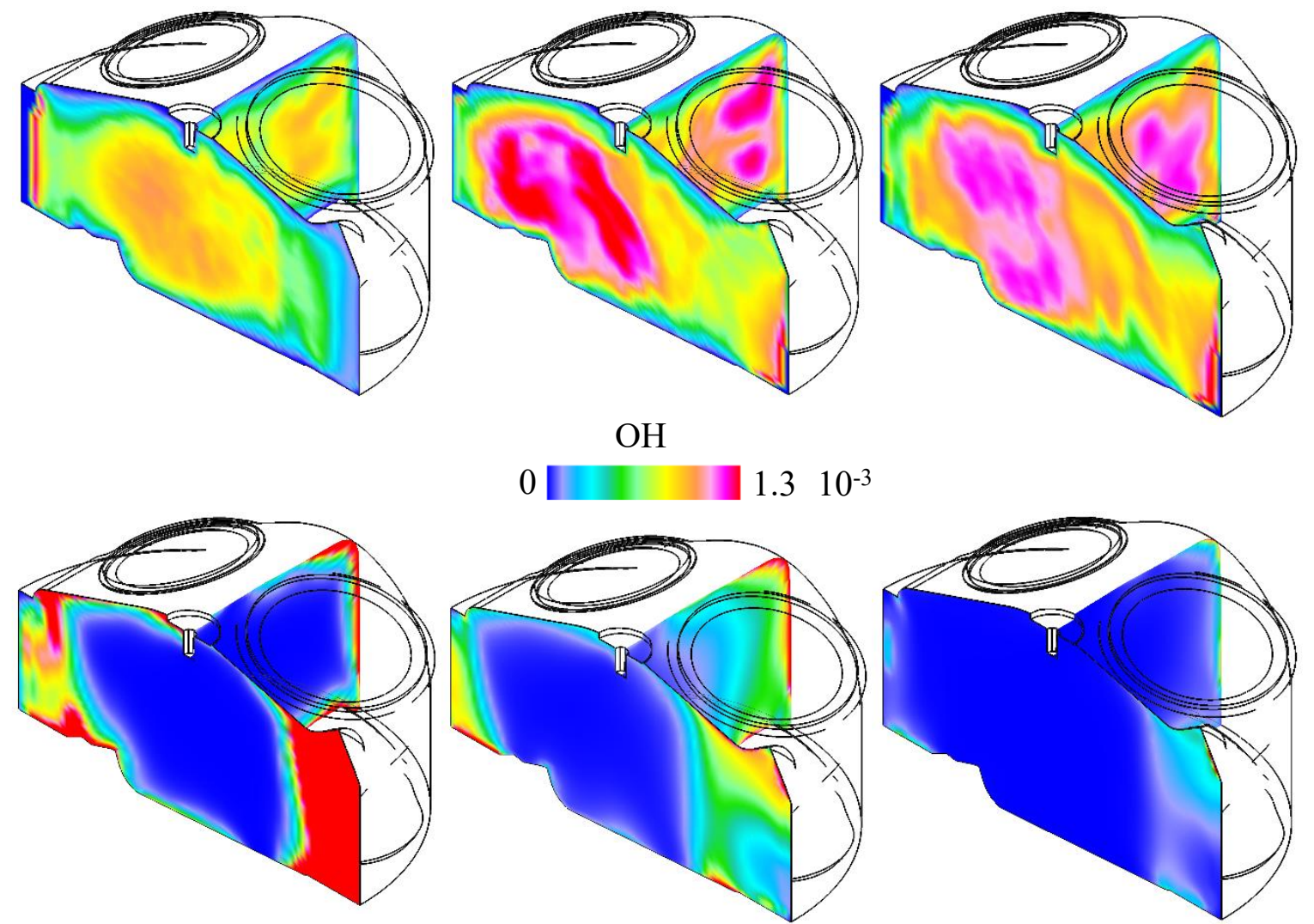

Number density (1/cc)

1 1 $10^{9}$

(c) $3000-90$
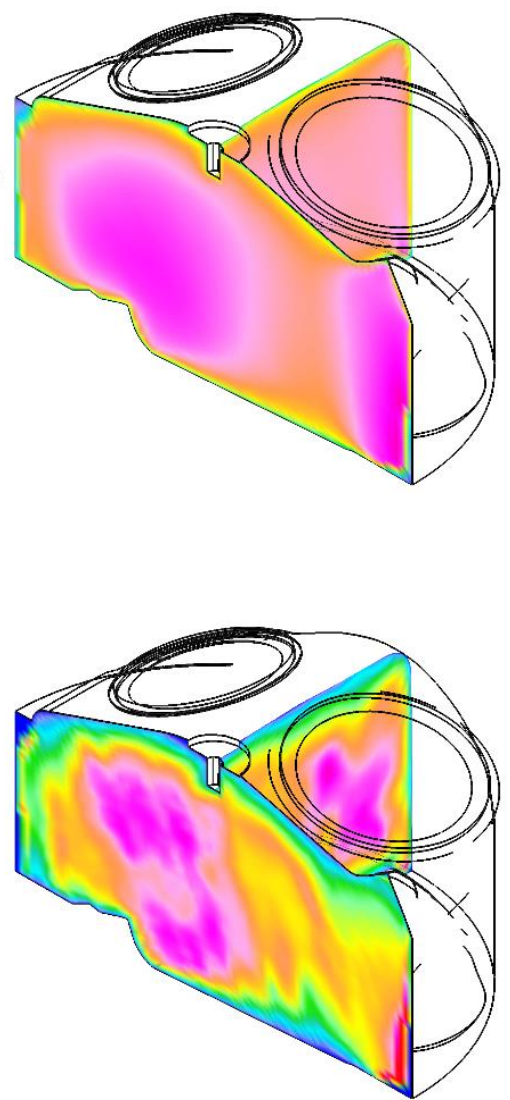


\subsection{Effect of Engine Load on PM Emissions}

The engine torque is varied from $60 \mathrm{~N} \mathrm{~m}$ to $120 \mathrm{~N} \mathrm{~m}$ with intervals of $30 \mathrm{~N} \mathrm{~m}$ to represent the low-, medium- and high-load conditions, respectively at the fixed engine speed of $2300 \mathrm{rpm}$. Generally, both simulated and measured pressure curves exhibit close resemblance with each other despite the slight over-predictions before the peak values across the engine loads in Figure 14. The estimated peak pressures stay within a 1\% margin from their experimental values. As shown in Figure 15, the computational results of soot stay within the same order of magnitude as the measured values. The comparison of normalised results based on 2300-90 reflects the accurate replication of experimental trends of number density and mass density due to the change in engine load.

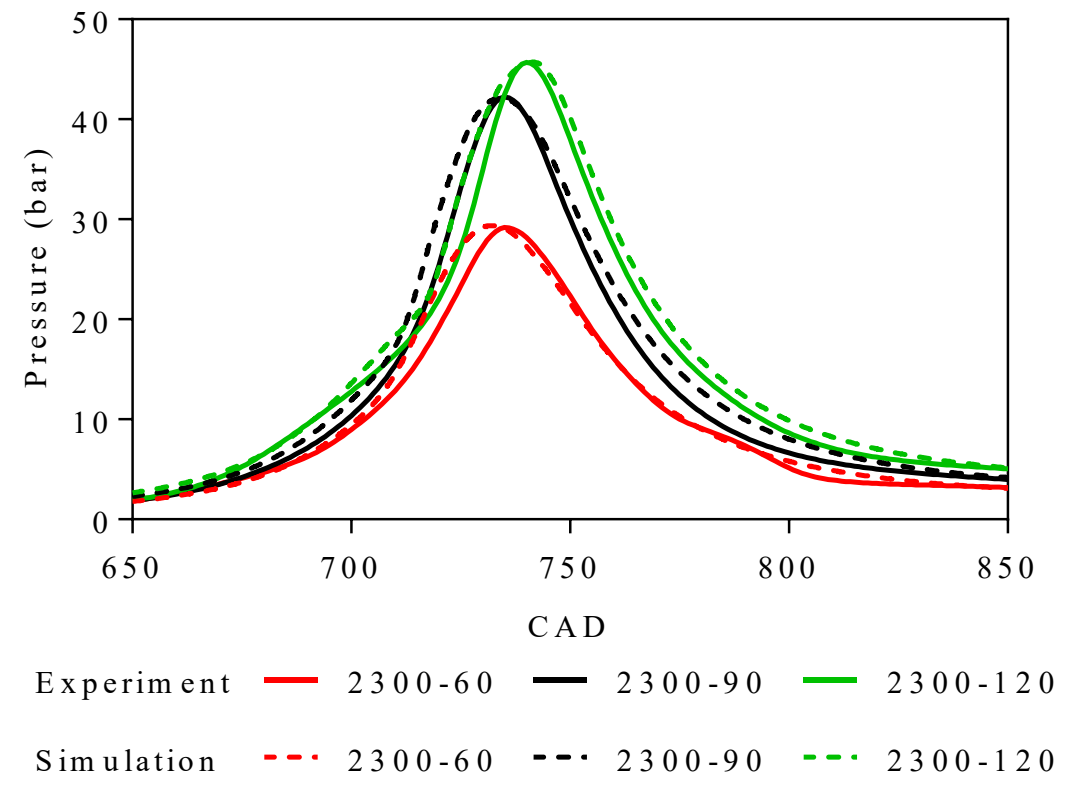

Figure 14 Measured and computed in-cylinder pressures for different engine loads. 

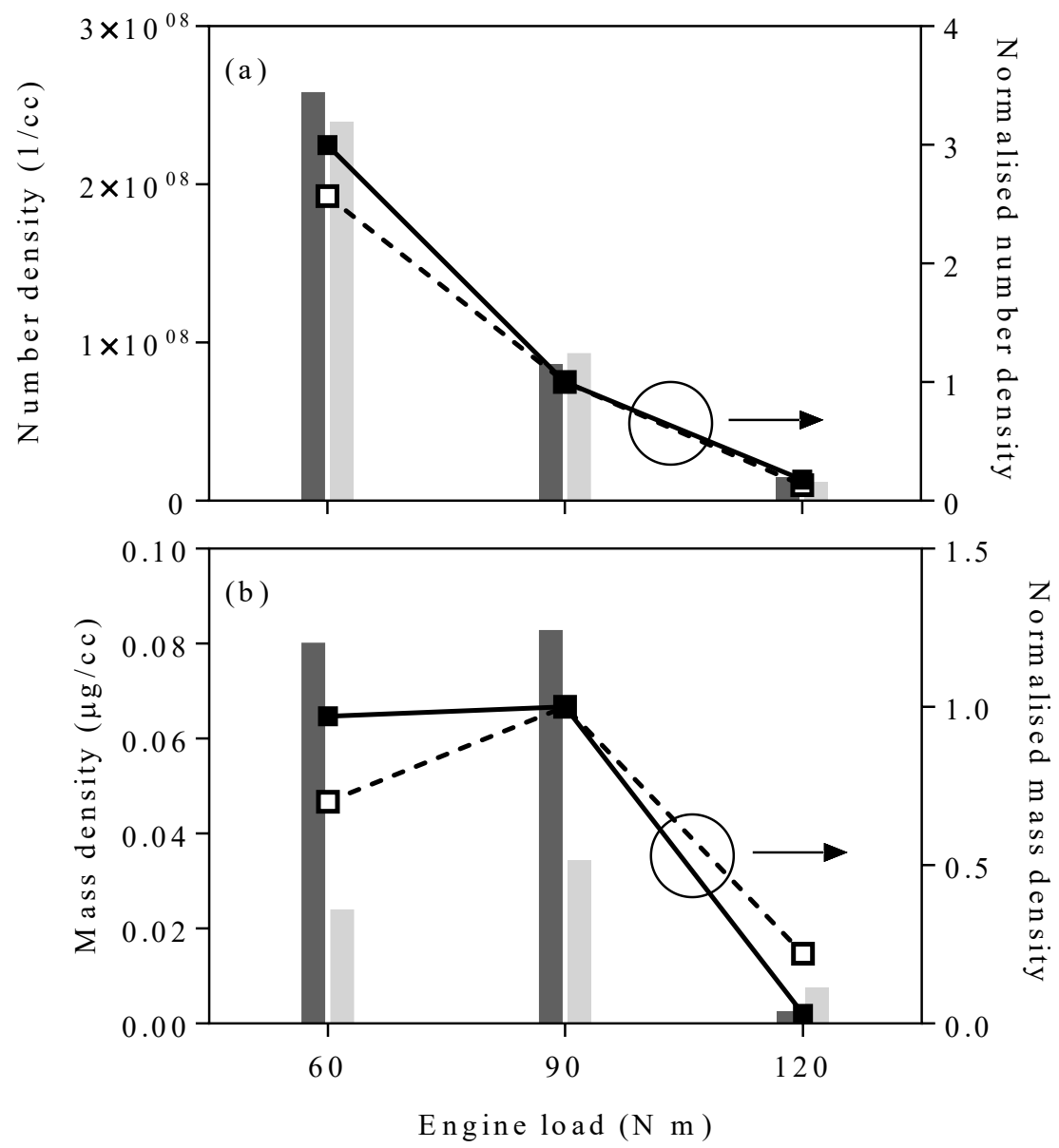

$\mathrm{Number/M}$ ass density

Normalised number/mass density

Experiment

Experiment

Simulation

-ㅁ. Sim ulation

Figure 15 Measured and computed (a) number density and (b) mass density of soot and their normalised values based on the reference case for different engine loads.

Increasing engine load requires a larger amount of fuel to be injected and both higher pressures at the intake manifold and during injection to facilitate spray atomisation. The role of injection pressure in affecting in-cylinder mixing level is clearly pinpointed in Figure 16. Upon SOI, swirl motion becomes stronger in which the swirl ratio reaches a peak value before decreasing after EOI. The swirl intensity is commensurate with the injection pressure and engine load. Likewise, there is an apparent rise in turbulence kinetic energy during fuel injection when the engine load increases. At 2300-120, the maximum turbulence kinetic energy after SOI is larger by $33 \%$ and $25 \%$ as compared to those at $60 \mathrm{~N} \mathrm{~m}$ and $90 \mathrm{~N} \mathrm{~m}$, respectively. This rise due to 
increased injection pressure was also captured in the work by Kim et al. ${ }^{60}$ for all the SOI timings studied.

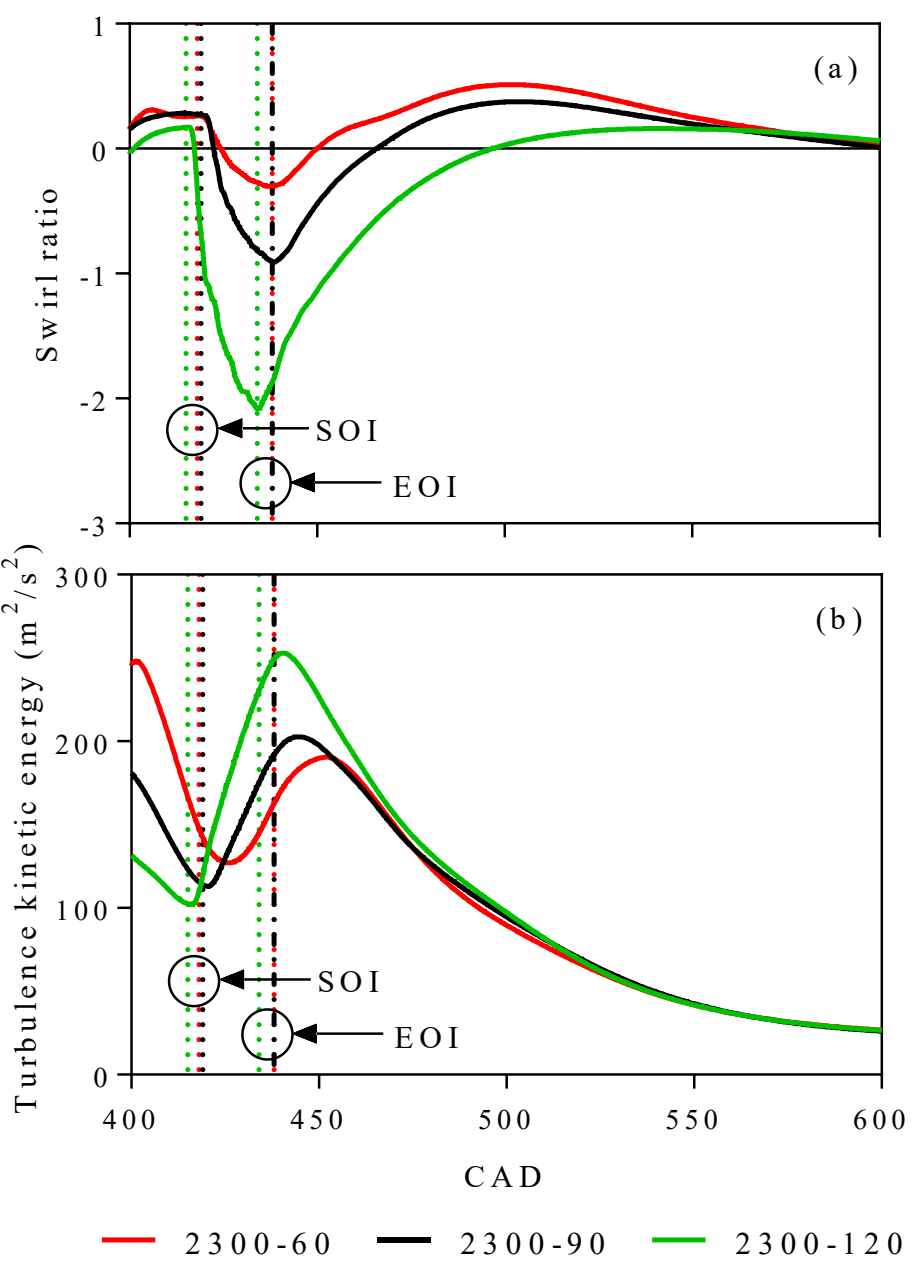

Figure 16 (a) Swirl ratio and (b) turbulence kinetic energy as a function of CAD for different engine loads.

At high-load condition, increased flow intensity due to higher intake and injection pressures is beneficial to fuel spray vaporisation ${ }^{60}$ throughout the injection period as evidenced in Figure 17. As engine load increases, the amount of liquid fuel droplets reduces drastically, along with diminished sizes due to faster initial vaporisation despite the larger mass of fuel injected. At $120 \mathrm{~N} \mathrm{~m}$, the wide region of high equivalence ratios in Figure 17(b)(iii) is indicative of strong fuel evaporation. Total mass of liquid film caused by spray impingement is plotted in Figure 18 in which the highest film mass is observed for 2300-120. However, due to the enhanced flow, the liquid film at $120 \mathrm{~N} \mathrm{~m}$ disintegrates the earliest by film stripping and breakup as compared to low-load conditions. This, in turn, allows longer time for fuel-rich pockets to mix with air evenly. 
(a) After 10 CAD SOI

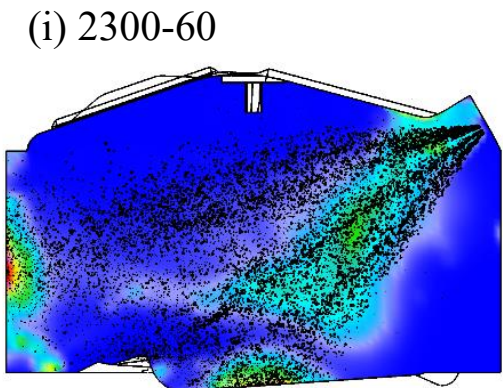

(ii) $2300-90$

(iii) $2300-120$
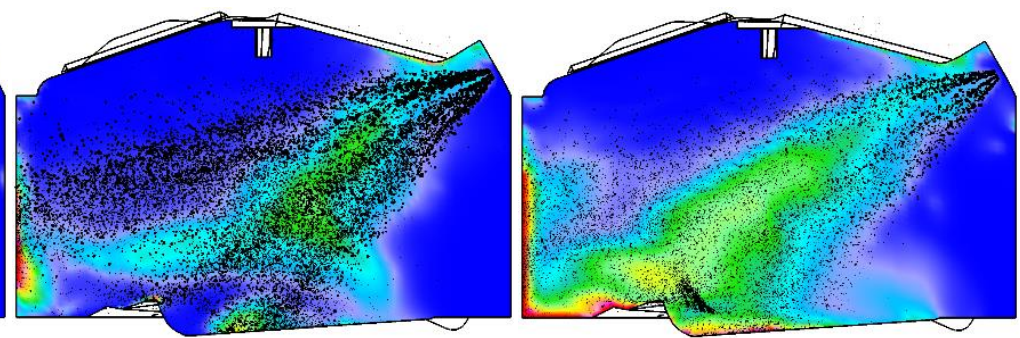

Equivalence ratio

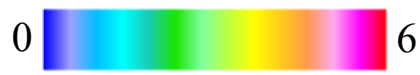

(b) EOI

(i) $2300-60$

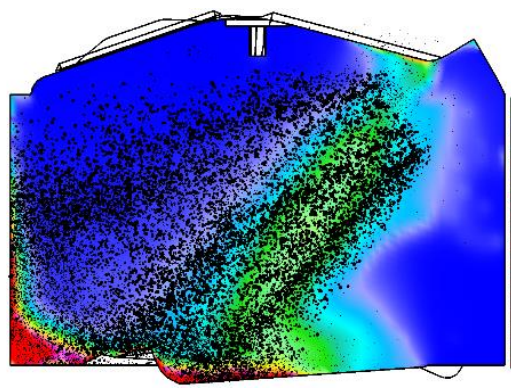

(ii) $2300-90$

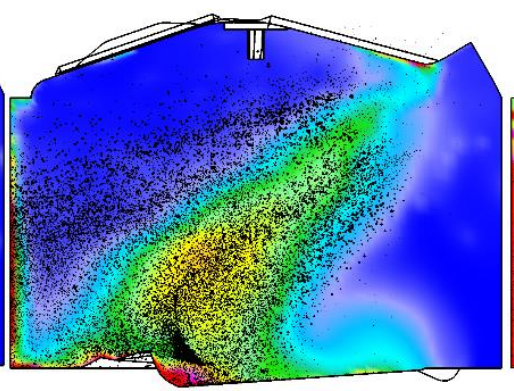

Equivalence ratio

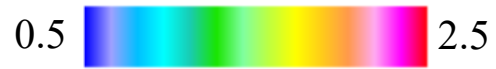

(iii) $2300-120$

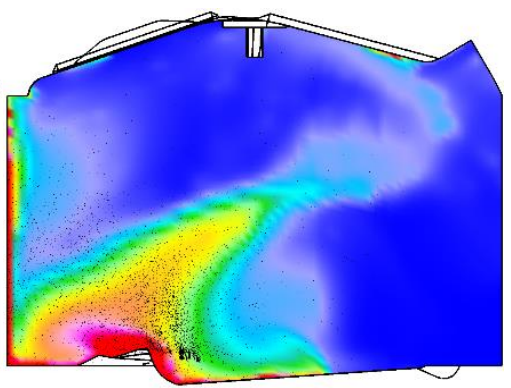

2.5

Figure 17 In-cylinder distributions of equivalence ratio superimposed with fuel droplets at (a) $10 \mathrm{CAD}$ after SOI and (b) EOI for engine loads of (i) $60 \mathrm{~N} \mathrm{~m}$, (ii) $90 \mathrm{~N} \mathrm{~m}$ and (iii) $120 \mathrm{~N} \mathrm{~m}$.

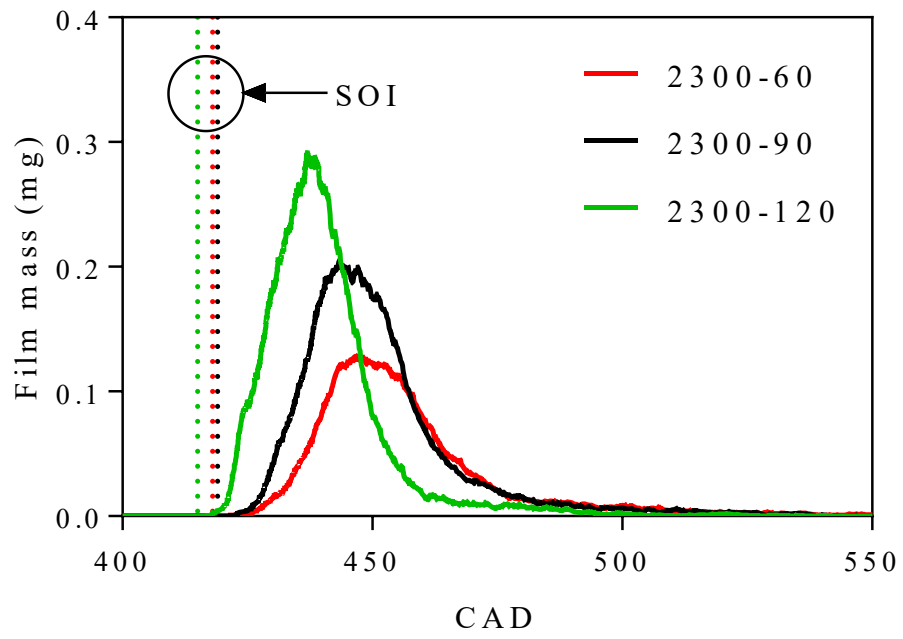

Figure 18 Total mass of liquid fuel film formed as a function of CAD for different engine loads. 
The outcome of air-fuel mixing at different engine loads is manifested through in-cylinder spatial distributions of equivalence ratio at SI timing in Figure 19. Due to the larger amount of fuel injected, the overall in-cylinder equivalence ratio increases slightly at higher engine loads. While small fuel-rich pockets are present near the right cylinder walls, critical fuel-rich region is located close to the combustion dome on the left side of cylinder. As the engine load increases, the rich region is shifted further away from the spark plug towards the left periphery. This subsequently turns out to be beneficial for fuel combustion as the areas near the ignition source need to be kept close to the stoichiometric condition to minimise PM formation.

(a) $2300-60$

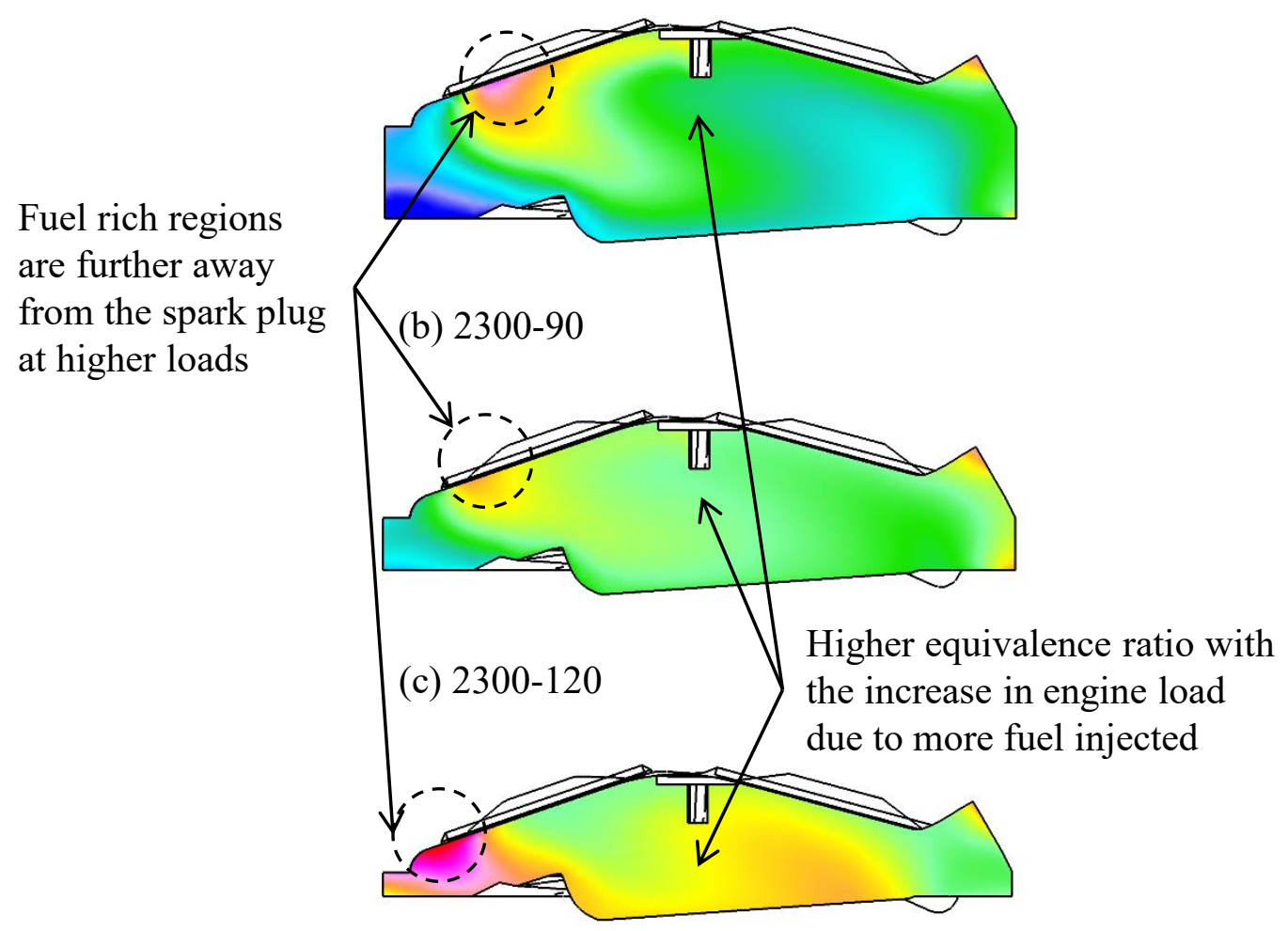

Equivalence ratio

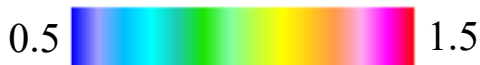

Figure 19 In-cylinder distributions of equivalence ratio at SI timing for engine loads of (a) 60 $\mathrm{N} \mathrm{m}$, (b) $90 \mathrm{~N}$ m and (c) $120 \mathrm{~N} \mathrm{~m}$.

Unlike those at high-load conditions, the equivalence ratio distribution at $60 \mathrm{~N} \mathrm{~m}$ as displayed in Figure 19(a) features relatively leaner regions at bottom part and right side of the combustion chamber. The uneven mixture distribution with higher level of stratification at low load is a direct consequence of advanced SI timing which shortens the mixing time. Furthermore, as 
visualised in Figure 20(a), a larger count of fuel droplets remains not volatilised at SI timing for the lowest load of $60 \mathrm{~N} \mathrm{~m}$. There is an apparent reduction in the amount of fuel droplets present at SI timing as the engine load is increased to $120 \mathrm{~N} \mathrm{~m}$. Apart from the delayed SI, enhanced mixing intensity due to increased injection pressures at higher engine loads improves fuel vaporisation, thus diminishing the amount of remaining fuel droplets as the cycle approaches the event of SI.

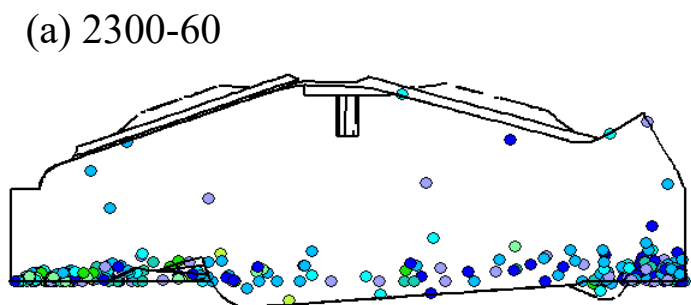

(b) $2300-90$

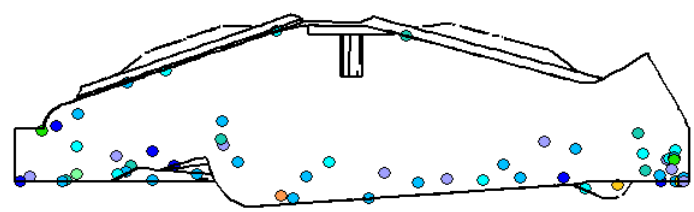

(c) $2300-120$

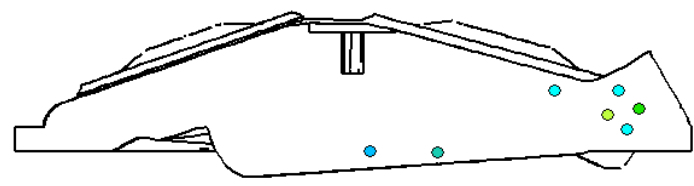

Droplet diameter $(\mu \mathrm{m})$

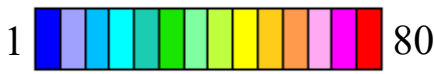

Figure 20 Fuel droplets coloured by their diameters at SI timing for engine loads of (a) $60 \mathrm{~N}$ m, (b) $90 \mathrm{~N} \mathrm{~m}$ and (c) $120 \mathrm{~N} \mathrm{~m}$.

From Figure 21, flame front propagates the fastest at $120 \mathrm{~N} \mathrm{~m}$ as the high-temperature region expands the furthest into the cylinder peripheries. This is corroborated by the experimental observation of increasing flame propagation speed extracted from planar flame images as the load became higher ${ }^{61}$. As engine load increases, the distributions of A4 and soot particle number are located closer to the cylinder peripheries which are in accordance to the fuel-air mixture distributions shown in Figure 19. Apart from the heavy consumption of A4 at 230060 , high soot number density can be attributed to carbonisation of the remaining liquid fuel droplets displayed in Figure 20(a). At high engine load of $120 \mathrm{~N} \mathrm{~m}$, low-temperature zones 
close to the cylinder walls, even with concentrated A4, turn out unfavourable for inception of nascent soot particles.

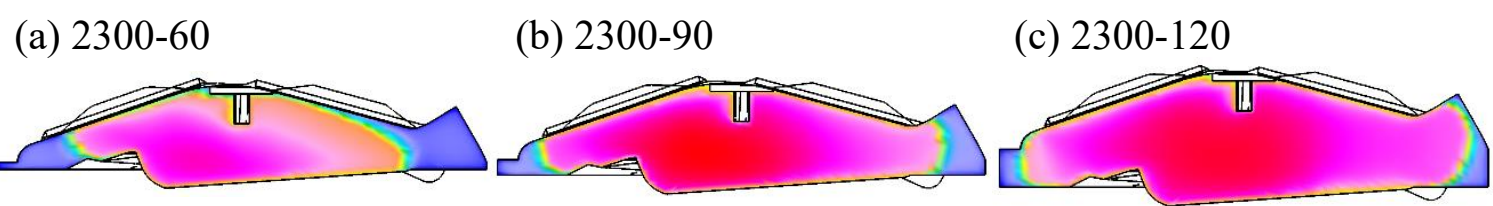

Temperature $(\mathrm{K})$

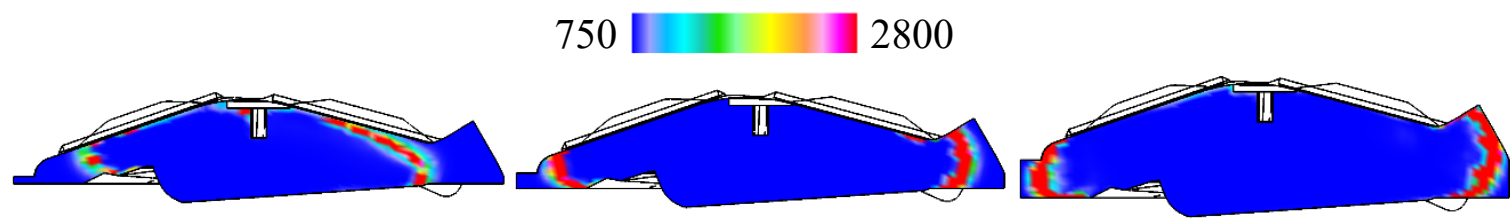

A4

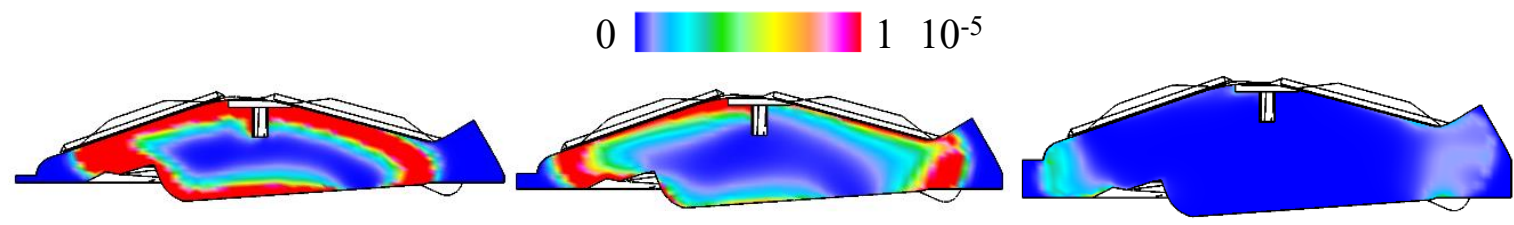

Number density (1/cc)

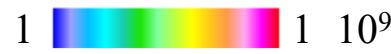

Figure 21 In-cylinder distributions of temperature, mass fractions of A4 and number density of soot for engine loads of (a) $60 \mathrm{~N} \mathrm{~m}$, (b) $90 \mathrm{~N} \mathrm{~m}$ and (c) $120 \mathrm{~N} \mathrm{~m}$ at $40 \mathrm{CAD}$ after SI.

Inspecting Figure 22 reveals that high-temperature areas within the cylinder exhibit effective post-flame oxidation of soot particles by $\mathrm{OH}$ radicals towards the end of combustion across all engine loads. Comparatively, lower in-cylinder temperature at low engine load of $60 \mathrm{~N} \mathrm{~m}$ deteriorates the oxidation rate with significantly higher soot number density observed near left and back wall peripheries. On the other hand, soot particles are largely oxidised at high-load condition with the residue concentrated at the left wall zones lacking $\mathrm{OH}$ radicals. Additionally, delayed SI timings at higher engine loads benefit the eventual emissions by shortening the residence time of soot particles before EVO. 
(a) $2300-60$

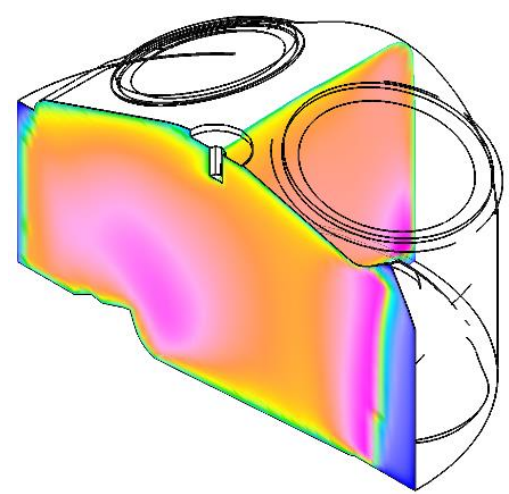

(b) $2300-90$

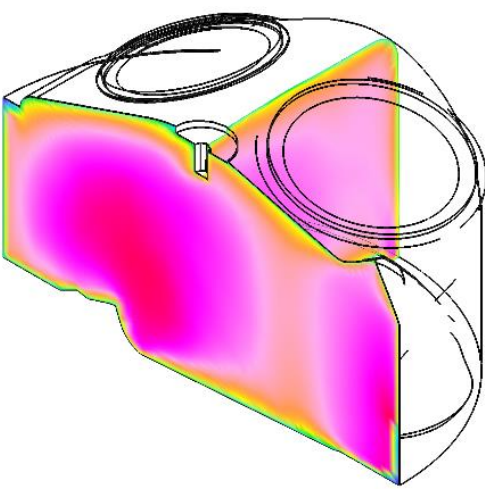

Temperature (K)

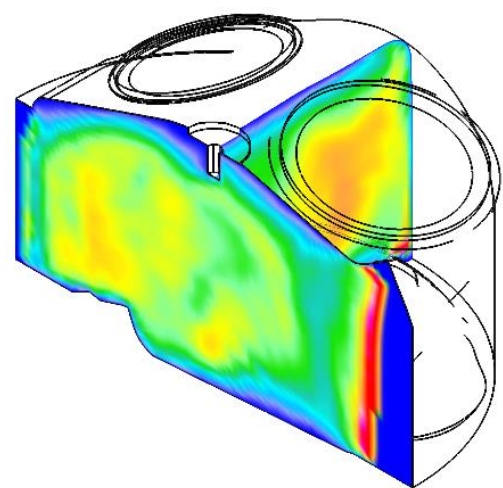

500 【 2400

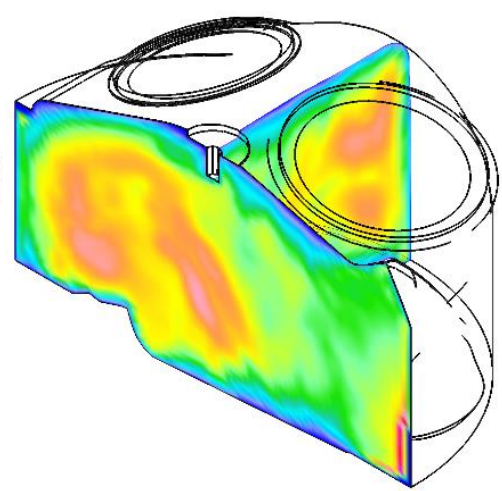

$\mathrm{OH}$
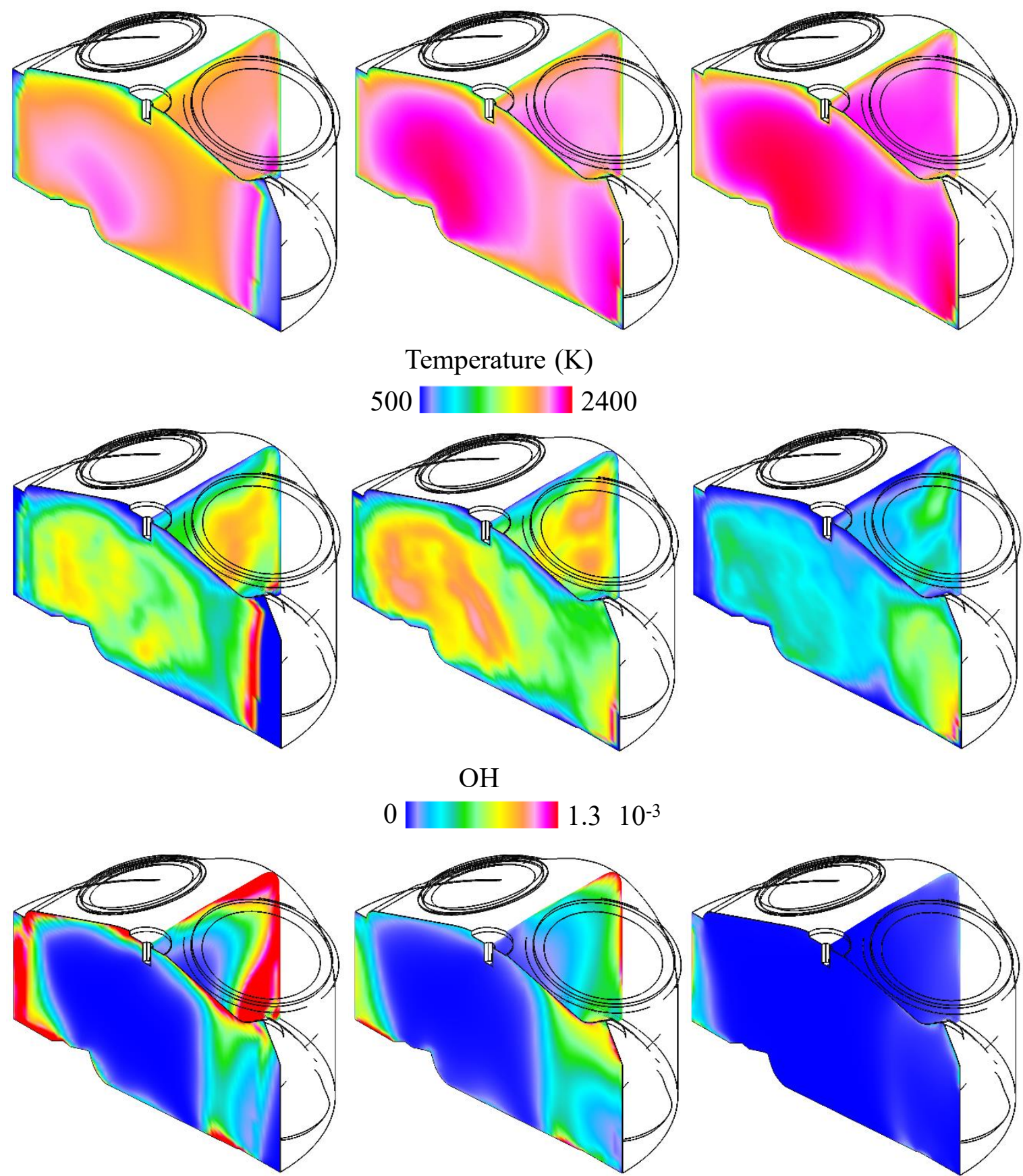

Number density $(1 / \mathrm{cc})$

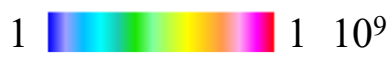

Figure 22 In-cylinder distributions of temperature, mass fractions of $\mathrm{OH}$ radicals and number density of soot for engine loads of (a) $60 \mathrm{~N} \mathrm{~m}$, (b) $90 \mathrm{~N} \mathrm{~m}$ and (c) $120 \mathrm{~N} \mathrm{~m}$ at $60 \mathrm{CAD}$ after TDC during the power stroke. 


\section{PM Formation Mechanisms in GDI Engines under Homogeneous Stoichiometric Operations}

Based on the reference case of 2300-90, the counter-clockwise nature of tumble flow plays a decisive role in distributing fuel and air spatially to achieve a homogenous charge in the wallguided GDI engine. During SOI, intense spray-wall impingement leads to formation and development of liquid fuel film. Through laser-induced fluorescence imaging, Stevens and Stepper ${ }^{62}$ captured the film formation on piston top for early fuel injection. Here, $76 \%$ of the maximum film mass is formed on the piston while that on the cylinder wall accounts for roughly $20 \%$. After EOI, film stripping, breakup and evaporation take place effectively. The resulting fuel-rich regions grow and spread upwards from the piston surface into the bulk of combustion chamber. The size of fuel-rich pockets near the piston as compared to that near the wall further highlights the severity of piston wetting.

Hentschel et al. ${ }^{63}$ visualised fuel distribution in a GDI engine with optical access using laserinduced fluorescence. The optical images of fuel vaporisation for early injection (410 CAD during the intake stroke) are set as a benchmark to evaluate the simulated mixing process in the present work as illustrated in Figure 23. The field of view is located centrally in the cylinder. The comparisons are made qualitatively due to the differences in engine specifications and operating parameters. Nonetheless, temporal development of computed fuel distribution is in coherent agreement with the optical diagnostics, leading to the formation of a nearly homogeneous charge. During the compression stroke depicted in Figure 23(a)(iii)-(iv) and (b)(iii)-(iv), higher fuel concentration is transported and located on the left side of cylinder (near the exhaust port). 
(a) Optical engine

(i) $40 \mathrm{CAD}$ after $\mathrm{SOI}$

(ii) $70 \mathrm{CAD}$ after $\mathrm{SOI}$

(iii) $160 \mathrm{CAD}$ after SO

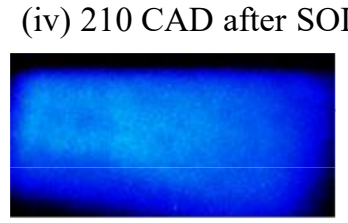

(b) Simulation

(i) $40 \mathrm{CAD}$ after $\mathrm{SOI}$

(ii) $70 \mathrm{CAD}$ after $\mathrm{SOI}$

(iii) $160 \mathrm{CAD}$ after $\mathrm{SOI}$

(iv) $210 \mathrm{CAD}$ after SOI
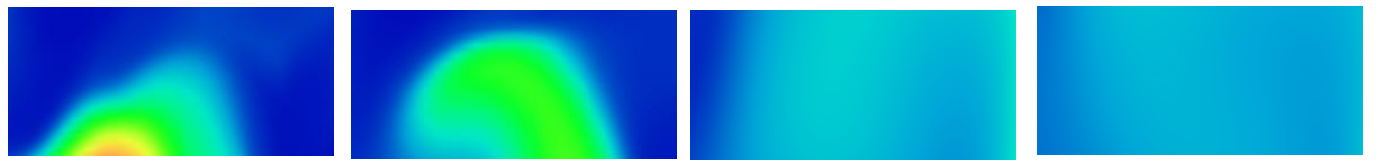

Fuel density

Minimum

Maximum

Figure 23 (a) Laser-induced fluorescence of liquid and gaseous phases of fuel and (b) simulated fuel mass fraction at (i) $40 \mathrm{CAD}$, (ii) $70 \mathrm{CAD}$, (iii) $160 \mathrm{CAD}$ and (iv) $210 \mathrm{CAD}$ after their respective SOI timings.

Fuel droplets which remain unevaporated during SI timing are visualised in Figure 24. The droplets are mainly scattered around the piston crown with diameters ranging from $4 \mu \mathrm{m}$ to 60 $\mu \mathrm{m}$. The source of fuel droplets surviving up to the event of SI can be associated with the following in-cylinder engine phenomena:

i. Fuel droplets fail to undergo further breakup and vaporise after injection and spray atomisation. This reflects poor in-cylinder conditions to facilitate fuel vaporisation and mixing.

ii. Fuel droplets rebound or splash into smaller droplets after impacting wall surfaces. Along with the newly injected fuel, they remain as liquid droplets as the engine cycle continues.

iii. Fuel droplets stripped from the liquid film are subjected to shortened time for evaporation, thus persisting till the event of SI. 


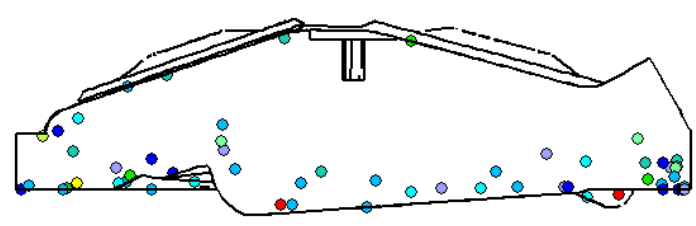

Droplet diameter $(\mu \mathrm{m})$

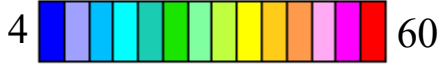

Figure 24 Fuel droplets coloured by their diameters at SI timing.

The resulting in-cylinder mixture distribution at SI timing is represented through equivalence ratio distributions in Figure 25. While the overall mixture approaches the stoichiometric state in the cylinder, areas of inhomogeneity and stratification can be observed near the left cylinder peripheries. Coherently, the top view of equivalence ratio demonstrates that the left domain of combustion chamber is richer in fuel than that of the right counterpart. Meanwhile, the side view of central plane of the cylinder reveals lowered mixture inhomogeneity with slightly higher equivalence ratio observed at the piston region as a consequence of piston wetting. The combustion mode is, therefore, more accurately characterised as theoretically homogeneous or quasi-homogeneous due to the inevitable mixture stratification to a certain extent near the event of SI.

As depicted in Figure 26, soot is mainly generated on the left side of cylinder which can be attributed to the fuel-rich zones resulting from imperfect mixing as corroborated by Figure 25. At the same time, high number density and mass density of soot near the piston surface are potentially the undesirable outcome of direct carbonisation of remaining liquid fuel droplets shown in Figure 24. From Figure 27, the maximum mass of $\mathrm{C}_{2} \mathrm{H}_{2}$ formed is higher than that of A4 by nearly a factor of four. This is because $\mathrm{C}_{2} \mathrm{H}_{2}$ contributes to formation and growth of large $\mathrm{PAH}$ including A4. Soot particles nucleate and grow in number and mass along with increasing mass of $\mathrm{C}_{2} \mathrm{H}_{2}$ and $\mathrm{A} 4$. It is noteworthy that soot peaks to its maximum mass earlier than reaching its highest particle number by $12 \mathrm{CAD}$. This is coherent with the observation that the peak mass of $\mathrm{C}_{2} \mathrm{H}_{2}$ is attained earlier as compared to that of $\mathrm{A} 4$. 


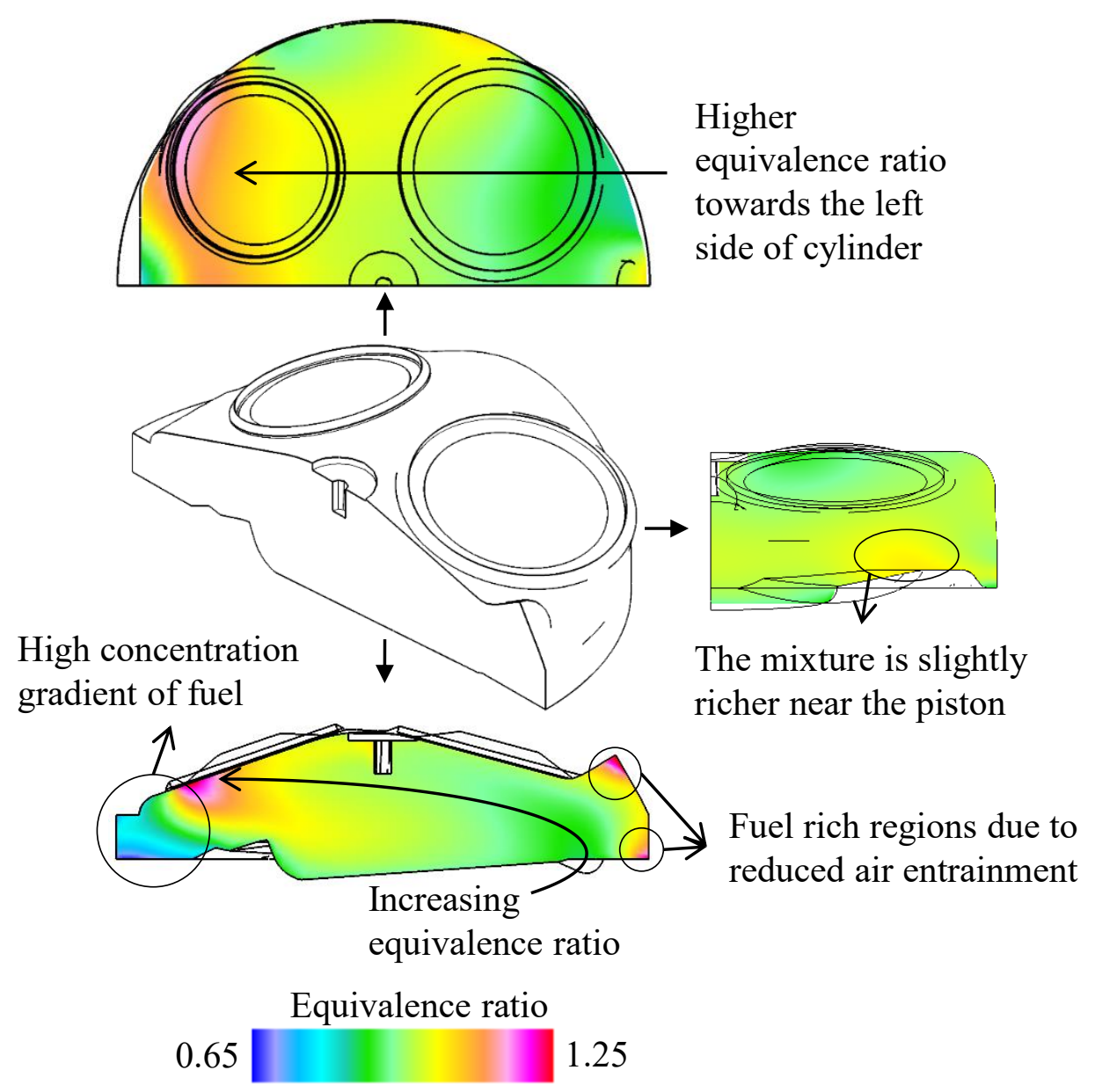

Figure 25 In-cylinder distributions of equivalence ratio across three cross-sectional planes at SI timing.
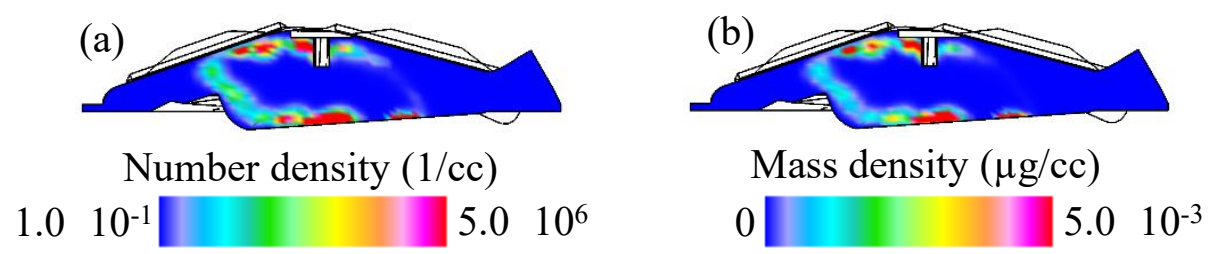

Figure 26 In-cylinder distributions of (a) number density and (b) mass density of soot at 19 CAD after SI. 


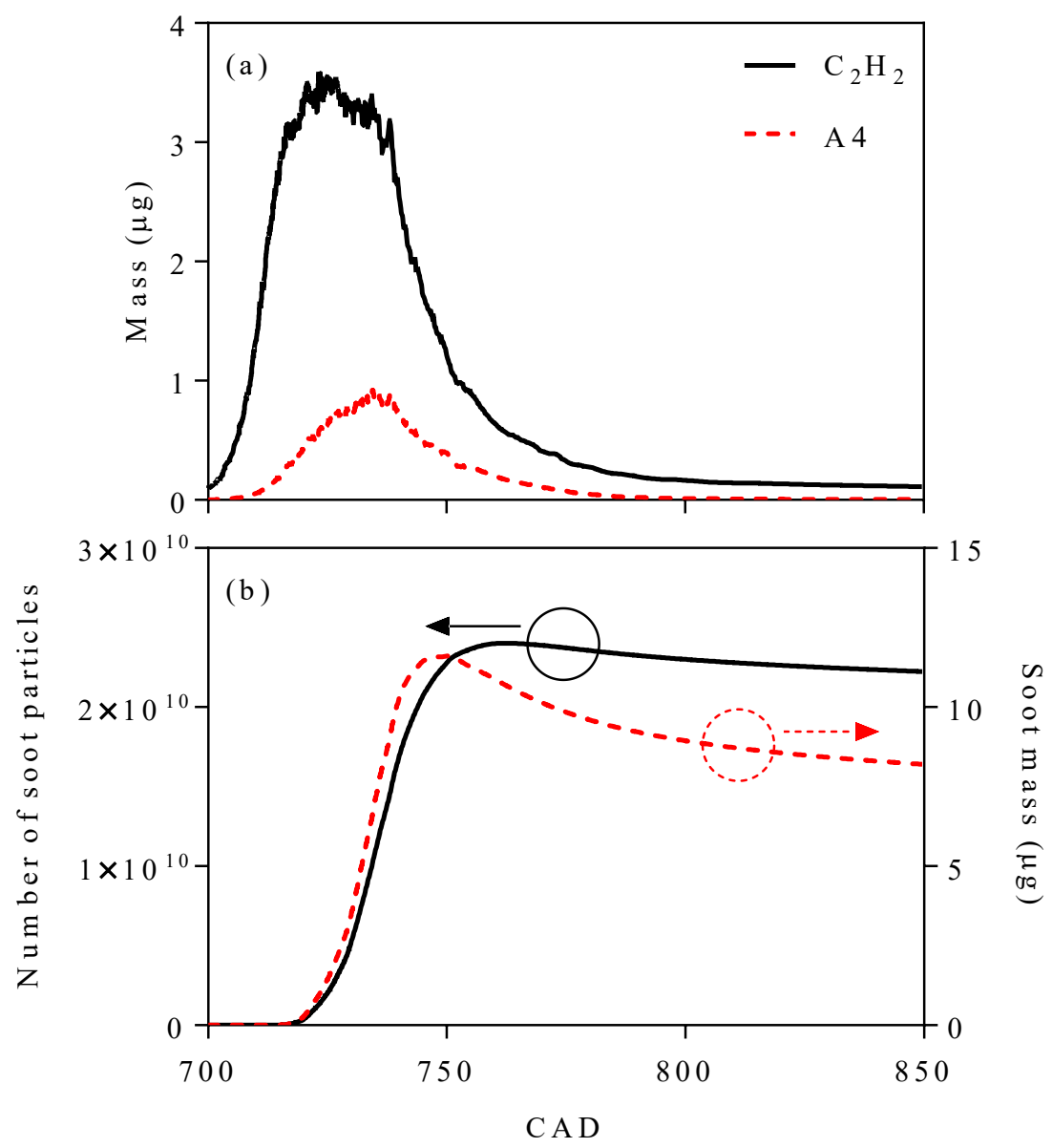

Figure 27 In-cylinder (a) mass of $\mathrm{C}_{2} \mathrm{H}_{2}$ and $\mathrm{A} 4$ and (b) number of soot particles and soot mass as a function of CAD.

As combustion proceeds, $\mathrm{C}_{2} \mathrm{H}_{2}$ and $\mathrm{A} 4$ have been mainly consumed with soot oxidation becoming the dominant mechanism to decrease particle number and size. Particularly, effective oxidation takes place under in-cylinder conditions of high temperature and large $\mathrm{OH}$ radical concentration. Towards the end of combustion, despite the high $\mathrm{OH}$ radical mass fraction at the back of cylinder, there is no marked cutback on soot due to the presence of $\mathrm{C}_{2} \mathrm{H}_{2}$ within the same region. Oxidation by $\mathrm{OH}$ radicals and surface growth due to $\mathrm{C}_{2} \mathrm{H}_{2}$ compete with one another and affect the soot distribution. At the same time, the left-skewed high-temperature region with concentrated $\mathrm{OH}$ radicals in explains the wider distributions of soot on the right side of cylinder. The overall conceptual understanding of the ultra-fine PM processes is portrayed in Figure 28, elucidating the roles and contributions of spray formation, mixture preparation, combustion and emission from the integrated point of view of CFD and chemical kinetics. 


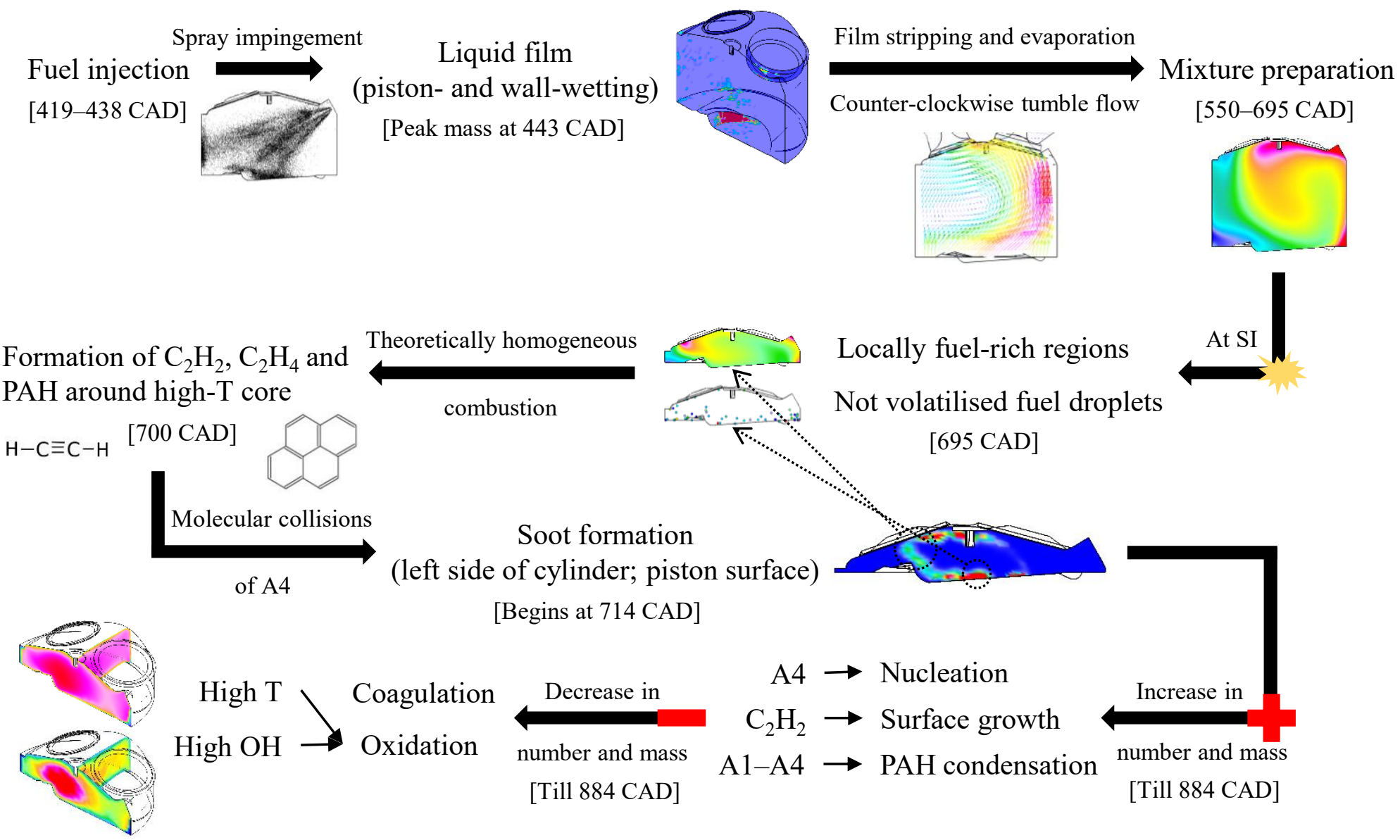

Figure 28 Conceptual understanding of the ultra-fine PM processes in the wall-guided GDI engine operating under a homogenous stoichiometric mode. 


\section{Conclusions}

The integrated CFD-chemical kinetic modelling approach is formulated to numerically characterise the in-cylinder events of GDI engines, emphasising the combustion and emission processes. Coupled with the TRF mechanism embedded with PAH chemistry and the DMZ partitioning method, the Detailed Chemistry model reproduces the measured in-cylinder pressures with the peak pressure predicted within a $1 \%$ margin for the reference case. Through the sectional method, computed number density of soot differs from the tailpipe measurement by $8 \%$ while its mass density is under-predicted by a factor of two. Reasonable agreement is preserved when the integrated approach is extended across the speed-load domain.

Engine speed controls in-cylinder flow field and time available for mixture preparation. When speed increases, higher flow velocity and stronger mixing intensity promote droplet breakup and vaporisation. The level of mixture homogeneity at SI timing improves at higher speed with reduced fuel-rich pockets. Consequently, number density of soot at $3000 \mathrm{rpm}$ is lowered by an order of magnitude and mass density decreases by a factor of six from those recorded at lower speeds. Increasing engine load dictates larger amount of fuel to be injected at higher injection pressure, accompanied by increased pressure at the intake manifold. Collectively, these lead to enhanced spray characteristics of fuel droplets. By SI timing, fuel-rich regions are located further away from the spark plug as the load increases. Also, the amount of remaining liquid droplets clearly decreases. Thus, a drop of an order of magnitude in number density of soot and a $78 \%$ decrease in mass density are seen as the load is increased to $120 \mathrm{~N} \mathrm{~m}$.

The conceptual understanding derived highlights two major sources of PM formation in the GDI engine as the presence of fuel-rich regions and the liquid fuel droplets which are not volatilised at SI timing. Imperfect mixture preparation can be traced back to fuel impingement on dome, piston and wall which forms liquid fuel film. Piston and wall wetting account for $76 \%$ and $20 \%$ of the maximum mass of total liquid film deposited, respectively. Film stripping and continuous fuel evaporation then create fuel-rich pockets in the cylinder. As a result of counter-clockwise tumble flow, in-cylinder equivalence ratio distribution at SI timing features an increasing contour from bottom right to upper left of the cylinder, along with the residual fuel droplets scattered around the piston crown.

Due to the mixture inhomogeneity, combustion mode in the GDI engine is more accurately termed theoretically homogenous combustion. Flame propagation from the central point of ignition is characterised by high-temperature core (up to $2800 \mathrm{~K}$ ) with accelerated production 
of $\mathrm{OH}$ radicals. Meanwhile, species related to surface growth $\left(\mathrm{C}_{2} \mathrm{H}_{2}\right)$ and soot precursor (A4) are distributed around the high-temperature core at about 1000-2000 K. Soot clouds become visible at $19 \mathrm{CAD}$ after SI at the left and bottom portions of cylinder. Particle inception from A4 and growth through HACARC mechanism and PAH condensation proceed with simultaneous oxidation by oxygen and $\mathrm{OH}$ radicals. Eventually, post-flame oxidation of soot particles dominates under high-temperature conditions with abundant $\mathrm{OH}$ radicals up to EVO.

\section{Acknowledgements}

The Ministry of Higher Education (MOHE) Malaysia is gratefully acknowledged for the financial support towards the study under the Fundamental Research Grant Scheme (FRGS) FRGS/1/2014/TK01/UNIM/01/1.

\section{References}

(1) Zhao, F.; Lai, M.-C.; Harrington, D. . Automotive Spark-Ignited Direct-Injection Gasoline Engines. Prog. Energy Combust. Sci. 1999, 25 (5), 437-562. https://doi.org/10.1016/S0360-1285(99)00004-0.

(2) Küsell, M.; Moser, W.; Philipp, M. Motronic MED7 for Gasoline Direct Injection Engines: Engine Management System and Calibration Procedures. SAE Tech. Pap. 1999. https://doi.org/10.4271/1999-01-1284.

(3) Andersson, J.; Giechaskiel, B.; Muñoz-Bueno, R.; Sandbach, E.; Dilara, P. Particle Measurement Programme (PMP) Light-Duty Inter-Laboratory Correlation Exercise (ILCE_LD) Final Report; 2007.

(4) Braisher, M.; Stone, R.; Price, P. Particle Number Emissions from a Range of European Vehicles. SAE Tech. Pap. 2010. https://doi.org/10.4271/2010-01-0786.

(5) Maricq, M. M.; Szente, J. J.; Jahr, K. The Impact of Ethanol Fuel Blends on PM Emissions from a Light-Duty GDI Vehicle. Aerosol Sci. Technol. 2012, 46 (5), 576583. https://doi.org/10.1080/02786826.2011.648780.

(6) Qian, Y.; Li, Z.; Yu, L.; Wang, X.; Lu, X. Review of the State-of-the-Art of Particulate Matter Emissions from Modern Gasoline Fueled Engines. Appl. Energy 2019, 238, 1269-1298. https://doi.org/10.1016/J.APENERGY.2019.01.179.

(7) Fushimi, A.; Kondo, Y.; Kobayashi, S.; Fujitani, Y.; Saitoh, K.; Takami, A.; Tanabe, K. Chemical Composition and Source of Fine and Nanoparticles from Recent Direct Injection Gasoline Passenger Cars: Effects of Fuel and Ambient Temperature. Atmos. Environ. 2016, 124, 77-84. https://doi.org/10.1016/J.ATMOSENV.2015.11.017.

(8) Heyder, J. Deposition of Inhaled Particles in the Human Respiratory Tract and Consequences for Regional Targeting in Respiratory Drug Delivery. In Proceedings of the American Thoracic Society; American Thoracic Society, 2004; Vol. 1, pp 315-320.

(9) Peters, A.; Veronesi, B.; Calderón-Garcidueñas, L.; Gehr, P.; Chen, L. C.; Geiser, M.; 
Reed, W.; Rothen-Rutishauser, B.; Schürch, S.; Schulz, H. Translocation and Potential Neurological Effects of Fine and Ultrafine Particles a Critical Update. Part. Fibre Toxicol. 2006, 3 (1), 13. https://doi.org/10.1186/1743-8977-3-13.

(10) Brugge, D.; Durant, J. L.; Rioux, C. Near-Highway Pollutants in Motor Vehicle Exhaust: A Review of Epidemiologic Evidence of Cardiac and Pulmonary Health Risks. Environ. Health 2007, 6, 23. https://doi.org/10.1186/1476-069X-6-23.

(11) Demuynck, J.; Favre, C.; Bosteels, D.; Hamje, H.; Andersson, J. Real-World Emissions Measurements of a Gasoline Direct Injection Vehicle without and with a Gasoline Particulate Filter; 2017. https://doi.org/10.4271/2017-01-0985.

(12) Maricq, M. M.; Podsiadlik, D. H.; Brehob, D. D.; Haghgooie, M. Particulate Emissions from a Direct-Injection Spark-Ignition (DISI) Engine. SAE Tech. Pap. 1999. https://doi.org/10.4271/1999-01-1530.

(13) Choi, K.; Kim, J.; Myung, C.-L.; Lee, M.; Kwon, S.; Lee, Y.; Park, S. Effect of the Mixture Preparation on the Nanoparticle Characteristics of Gasoline Direct-Injection Vehicles. Proc. Inst. Mech. Eng. Part D J. Automob. Eng. 2012, 226 (11), 1514-1524. https://doi.org/10.1177/0954407012445534.

(14) Barone, T. L.; Storey, J. M. E.; Youngquist, A. D.; Szybist, J. P. An Analysis of DirectInjection Spark-Ignition (DISI) Soot Morphology. Atmos. Environ. 2012, 49, 268-274. https://doi.org/10.1016/j.atmosenv.2011.11.047.

(15) Olmo, L.; Thornton, J. CFD Analysis of Mixture Formation and Combustion Process for High Performance DI Gasoline Engine. SAE Tech. Pap. 2005. https://doi.org/10.4271/2005-01-0214.

(16) Bonatesta, F.; La Rocca, S.; Hopkins, E.; Bell, D. Application of Computational Fluid Dynamics to Explore the Sources of Soot Formation in a Gasoline Direct Injection Engine. SAE Tech. Pap. 2014. https://doi.org/10.4271/2014-01-2569.

(17) Costa, M.; Marchitto, L.; Merola, S. S.; Sorge, U. Study of Mixture Formation and Early Flame Development in a Research GDI (Gasoline Direct Injection) Engine through Numerical Simulation and UV-Digital Imaging. Energy 2014, 77, 88-96. https://doi.org/10.1016/j.energy.2014.04.114.

(18) Costa, M.; Sorge, U.; Sementa, P.; Vaglieco, B. M. CFD Modeling of a Mixed Mode Boosted GDI Engine and Performance Optimization for the Avoidance of Knocking. In Simulation and Modeling Methodologies, Technologies and Applications; Obaidat, M. S., Ören, T., Kacprzyk, J., Filipe, J., Eds.; Springer, Cham, 2015; pp 195-215. https://doi.org/10.1007/978-3-319-26470-7_10.

(19) Tan, J. Y.; Bonatesta, F.; Ng, H. K.; Gan, S. Developments in Computational Fluid Dynamics Modelling of Gasoline Direct Injection Engine Combustion and Soot Emission with Chemical Kinetic Modelling. Appl. Therm. Eng. 2016, 107, 936-959. https://doi.org/10.1016/j.applthermaleng.2016.07.024.

(20) Aubagnac-Karkar, D.; Michel, J.-B.; Colin, O.; Vervisch-Kljakic, P. E.; Darabiha, N. Sectional Soot Model Coupled to Tabulated Chemistry for Diesel RANS Simulations. Combust. Flame 2015, $162 \quad$ (8), https://doi.org/10.1016/J.COMBUSTFLAME.2015.03.005. 
(21) Etheridge, J.; Mosbach, S.; Kraft, M.; Wu, H.; Collings, N. Modelling Soot Formation in a DISI Engine. Proc. Combust. Inst. 2011, 33 (2), 3159-3167. https://doi.org/10.1016/j.proci.2010.07.039.

(22) Wang, B.; Mosbach, S.; Schmutzhard, S.; Shuai, S.; Huang, Y.; Kraft, M. Modelling Soot Formation from Wall Films in a Gasoline Direct Injection Engine Using a Detailed Population Balance Model. Appl. Energy 2016, 163, 154-166. https://doi.org/10.1016/j.apenergy.2015.11.011.

(23) Dong, Z.; Shuai, S.; Wang, Z.; Zhao, H. CFD Modeling of Mixture Preparation and Soot Formation in a Downsized Gasoline Direct Injection Engine. SAE Tech. Pap. 2016. https://doi.org/10.4271/2016-01-0586.

(24) Gong, Z.; Feng, L.; Wang, Z. Experimental and Numerical Study of the Effect of Injection Strategy and Intake Valve Lift on Super-Knock and Engine Performance in a Boosted GDI Engine. Fuel 2019, 249, 309-325. https://doi.org/10.1016/J.FUEL.2019.03.005.

(25) An, Y.; Li, X.; Teng, S.; Wang, K.; Pei, Y.; Qin, J.; Zhao, H. Development of a Soot Particle Model with PAHs as Precursors through Simulations and Experiments. Fuel 2016, 179, 246-257. https://doi.org/10.1016/J.FUEL.2016.03.100.

(26) Kim, J.; Kim, N.; Min, K. Numerical Investigation of Soot Emission in Direct-Injection Spark-Ignition Engines Using a Detailed Soot Model Framework; 2016. https://doi.org/10.4271/2016-01-0580.

(27) Jiao, Q.; Reitz, R. D. Modeling Soot Emissions from Wall Films in a Direct-Injection Spark-Ignition Engine. Int. J. Engine Res. 2014, 16 (8), 994-1013. https://doi.org/10.1177/1468087414562008.

(28) Mcenally, C.; Pfefferle, L. Improved Sooting Tendency Measurements for Aromatic Hydrocarbons and Their Implications for Naphthalene Formation Pathways. Combust. Flame 2007, 148 (4), 210-222. https://doi.org/10.1016/j.combustflame.2006.11.003.

(29) Bonatesta, F.; Chiappetta, E.; La Rocca, A. Part-Load Particulate Matter from a GDI Engine and the Connection with Combustion Characteristics. Appl. Energy 2014, 124, 366-376. https://doi.org/10.1016/j.apenergy.2014.03.030.

(30) Sciortino, D.; Bonatesta, F.; Hopkins, E.; Yang, C.; Morrey, D.; Sciortino, D. D.; Bonatesta, F.; Hopkins, E.; Yang, C.; Morrey, D. A Combined Experimental and Computational Fluid Dynamics Investigation of Particulate Matter Emissions from a Wall-Guided Gasoline Direct Injection Engine. Energies 2017, 10 (9), 1408. https://doi.org/10.3390/en10091408.

(31) An, Y.; Pei, Y.; Qin, J.; Zhao, H.; Teng, S.; Li, B.; Li, X. Development of a PAH (Polycyclic Aromatic Hydrocarbon) Formation Model for Gasoline Surrogates and Its Application for GDI (Gasoline Direct Injection) Engine CFD (Computational Fluid Dynamics) Simulation. Energy 2016, 94, 367-379. https://doi.org/10.1016/J.ENERGY.2015.11.014.

(32) Pang, B.; Xie, M.-Z.; Jia, M.; Liu, Y.-D. Development of a Phenomenological Soot Model Coupled with a Skeletal PAH Mechanism for Practical Engine Simulation. Energy \& Fuels 2013, 27 (3), 1699-1711. https://doi.org/10.1021/ef400033f. 
(33) Appel, J.; Bockhorn, H.; Frenklach, M. Kinetic Modeling of Soot Formation with Detailed Chemistry and Physics: Laminar Premixed Flames of C2 Hydrocarbons. Combust. Flame 2000, 121 (1-2), 122-136. https://doi.org/10.1016/S00102180(99)00135-2.

(34) Raj, A.; Celnik, M.; Shirley, R.; Sander, M.; Patterson, R.; West, R.; Kraft, M. A Statistical Approach to Develop a Detailed Soot Growth Model Using PAH Characteristics. Combust. Flame 2009, $156 \quad$ (4), 896-913. https://doi.org/10.1016/j.combustflame.2009.01.005.

(35) Yakhot, V.; Orszag, S. A.; Thangam, S.; Gatski, T. B.; Speziale, C. G. Development of Turbulence Models for Shear Flows by a Double Expansion Technique. Phys. Fluids A Fluid Dyn. 1992, 4 (7), 1510-1520. https://doi.org/10.1063/1.858424.

(36) Rodi, W. Influence of Buoyancy and Rotation on Equations for the Turbulent Length Scale. In Symposium on Turbulent Shear Flows; London, 1979; pp 10.37-10.42.

(37) Rotondi, R.; Bella, G. Gasoline Direct Injection Spray Simulation. Int. J. Therm. Sci. 2006, 45 (2), 168-179. https://doi.org/10.1016/j.ijthermalsci.2005.06.001.

(38) Givler, S. D.; Raju, M.; Pomraning, E.; Senecal, P. K.; Salman, N.; Reese, R. Gasoline Combustion Modeling of Direct and Port-Fuel Injected Engines Using a Reduced Chemical Mechanism. SAE Tech. Pap. 2013. https://doi.org/10.4271/2013-01-1098.

(39) Kim, T.; Song, J.; Park, S. Effects of Turbulence Enhancement on Combustion Process Using a Double Injection Strategy in Direct-Injection Spark-Ignition (DISI) Gasoline Engines. Int. J. Heat Fluid Flow 2015, 56, 124-136. https://doi.org/10.1016/j.ijheatfluidflow.2015.07.013.

(40) Patterson, M. A.; Reitz, R. D. Modeling the Effects of Fuel Spray Characteristics on Diesel Engine Combustion and Emission. SAE International 1998. https://doi.org/10.4271/980131.

(41) Angelberger, C.; Poinsot, T.; Delhay, B. Improving Near-Wall Combustion and Wall Heat Transfer Modeling in SI Engine Computations. SAE Tech. Pap. 1997. https://doi.org/10.4271/972881.

(42) Bai, C.; Gosman, A. D. Development of Methodology for Spray Impingement Simulation. SAE International 1995. https://doi.org/10.4271/950283.

(43) Rosa, N. G.; Villedieu, P.; Dewitte, J.; Lavergne, G. A New Droplet-Wall Interaction Model. In 10th International Conference on Liquid Atomization and Spray Systems (ICLASS-2006); Kyoto, 2006.

(44) Bai, C.; Gosman, A. D. Mathematical Modelling of Wall Films Formed by Impinging Sprays. SAE Tech. Pap. 1996. https://doi.org/10.4271/960626.

(45) Friedrich, M. A.; Lan, H.; Wegener, J. L.; Drallmeier, J. A.; Armaly, B. F. A Separation Criterion With Experimental Validation for Shear-Driven Films in Separated Flows. $J$. Fluids Eng. 2008, 130 (5), 051301. https://doi.org/10.1115/1.2907405.

(46) Liang, L.; Stevens, J. G.; Farrell, J. T. A Dynamic Multi-Zone Partitioning Scheme for Solving Detailed Chemical Kinetics in Reactive Flow Computations. Combust. Sci. Technol. 2009, 181 (11), 1345-1371. https://doi.org/10.1080/00102200903190836. 
(47) Liang, L.; Naik, C. V.; Puduppakkam, K.; Wang, C.; Modak, A.; Meeks, E.; Ge, H.-W.; Reitz, R. D.; Rutland, C. Efficient Simulation of Diesel Engine Combustion Using Realistic Chemical Kinetics in CFD. SAE Tech. Pap. 2010. https://doi.org/10.4271/2010-01-0178.

(48) Marchal, C. Modélisation de La Formation et de l'oxydation Des Suies Dans Un Moteur Automobile, Université d'Orléans, 2008.

(49) La Rocca, A.; Bonatesta, F.; Fay, M. W.; Campanella, F. Characterisation of Soot in Oil from a Gasoline Direct Injection Engine Using Transmission Electron Microscopy. Tribol. Int. 2015, 86, 77-84. https://doi.org/10.1016/j.triboint.2015.01.025.

(50) Mao, Q.; van Duin, A. C. T.; Luo, K. H. Formation of Incipient Soot Particles from Polycyclic Aromatic Hydrocarbons: A ReaxFF Molecular Dynamics Study. Carbon N. Y. 2017, 121, 380-388. https://doi.org/10.1016/J.CARBON.2017.06.009.

(51) Smoluchowski, M. Versuch Einer Mathematischen Theorie Der Koagulationskinetik Kolloider Losungen. Zeitschrift f. Phys. Chemie, XCII 1917, 92, 129-168.

(52) Mauss, F.; Schäfer, T.; Bockhorn, H. Inception and Growth of Soot Particles in Dependence on the Surrounding Gas Phase. Combust. Flame 1994, 99 (3-4), 697-705. https://doi.org/10.1016/0010-2180(94)90064-7.

(53) Frenklach, M.; Wang, H. Detailed Modeling of Soot Particle Nucleation and Growth. Symp. Combust. 1991, 23 (1), 1559-1566. https://doi.org/10.1016/S00820784(06)80426-1.

(54) Whelan, I. A Study of Particulate Matter Emissions from Gasoline Direct Injection Engines, University College Dublin, 2013.

(55) Wallesten, J.; Lipatnikov, A.; Chomiak, J. Simulations of Fuel/Air Mixing, Combustion, and Pollutant Formation in a Direct Injection Gasoline Engine. SAE Tech. Pap. 2002. https://doi.org/10.4271/2002-01-0835.

(56) Jiao, Q.; Reitz, R. D. The Effect of Operating Parameters on Soot Emissions in GDI Engines. SAE Int. J. Engines 2015, 8 (3), 2015-01-1071. https://doi.org/10.4271/201501-1071.

(57) Costa, M.; Catapano, F.; Sementa, P.; Sorge, U.; Vaglieco, B. M. Mixture Preparation and Combustion in a GDI Engine under Stoichiometric or Lean Charge: An Experimental and Numerical Study on an Optically Accessible Engine. Appl. Energy 2016, 180, 86-103. https://doi.org/10.1016/J.APENERGY.2016.07.089.

(58) Kuwahara, K.; Ando, H. Diagnostics of In-Cylinder Flow, Mixing and Combustion in Gasoline Engines. Meas. Sci. Technol. 2000, 11 (6), R95-R111. https://doi.org/10.1088/0957-0233/11/6/202.

(59) An, Y.; Teng, S.; Li, X.; Qin, J.; Zhao, H.; Zhan, Z. S.; Hu, T. G.; Liu, B.; Zhong, J. Study of Polycyclic Aromatic Hydrocarbons Evolution Processing in GDI Engines Using TRF-PAH Chemical Kinetic Mechanism. SAE Tech. Pap. 2016. https://doi.org/10.4271/2016-01-0690.

(60) Kim, T.; Song, J.; Park, J.; Park, S. Numerical and Experimental Study on Effects of Fuel Injection Timings on Combustion and Emission Characteristics of a Direct- 
Injection Spark-Ignition Gasoline Engine with a $50 \mathrm{MPa}$ Fuel Injection System. Appl. Therm. Eng. 2018, 144, 890-900. https://doi.org/10.1016/J.APPLTHERMALENG.2018.09.007.

(61) Tatschl, R.; Riediger, H. PDF Modelling of Stratified Charge SI Engine Combustion. SAE Tech. Pap. 1998. https://doi.org/10.4271/981464.

(62) Stevens, E.; Steeper, R. Piston Wetting in an Optical DISI Engine: Fuel Films, Pool Fires, and Soot Generation. SAE Tech. Pap. 2001. https://doi.org/10.4271/2001-011203.

(63) Hentschel, W.; Block, B.; Hovestadt, T.; Meyer, H.; Ohmstede, G.; Richter, V.; Stiebels, B.; Winkler, A. Optical Diagnostics and CFD-Simulations to Support the Combustion Process Development of the Volkswagen FSI ${ }^{\circledR}$ Direct-Injection Gasoline Engine. SAE Tech. Pap. 2001. https://doi.org/10.4271/2001-01-3648. 